\title{
Análise da confiabilidade humana via redes Bayesianas: uma aplicação à manutenção de linhas de transmissão
}

\author{
EnRique López Droguett \\ Regilda da Costa Silva Menêzes
}

UFPE

\begin{abstract}
Resumo
A análise de confiabilidade humana (ACH) estuda a execução das ações humanas em um determinado sistema, considerando suas limitações e os fatores que influenciam no seu desempenho. A literatura apresenta os modelos de ACH de primeira e segunda geração. Esses modelos apresentam algumas deficiências. Dentre elas, destacam-se suposições irreais de independência e simples representação binária de eventos. Diante disso, apresentam uma grande dificuldade na modelagem das ações humanas. Este artigo mostra que modelar ações humanas por redes Bayesianas (RBs) proporciona uma maior flexibilidade às variáveis componentes de um determinado sistema, pois além de permitir uma representação mais realista da natureza dinâmica da interface homem-sistema, também representa a relação de dependência entre eventos e entre fatores de desempenho. Neste artigo, utilizam-se RBs para $\mathrm{ACH}$ em atividades de manutenção de linhas de transmissão.
\end{abstract}

Palavras-chave

Redes bayesianas, análise de confiabilidade humana, fatores de desempenho.

\section{Human reliability analysis through Bayesian networks: an application in maintenance of transmission lines}

\begin{abstract}
Human Reliability Analysis (HRA) has been used to study the execution of human actions and their interactions with a system, taking into account its limitations and factors influencing the human performance. The HRA methods can be categorized into the first and second generation models. These models present some shortcomings such as unrealistic independence assumptions and simple binary representation of events. Therefore, they present a significant deficiency in modeling human actions. In this paper it is described a methodology for modeling human actions through Bayesian belief networks (BBN). The methodology provides a greater flexibility as not it only allows for a more realistic representation of the dynamic nature of man-system, but also allows for representation of the relationship of dependence among the events and performance shaping factors. This methodology is demonstrated in the context of human reliability in activities of maintenance of transmission line.
\end{abstract}

Key words

Bayesian belief networks, human reliability analysis, performance shaping factors. 


\section{INTRODUÇ̃̃̃O}

De acordo com Swain \& Guttmann (1983), confiabilidade humana é a probabilidade de um procedimento ou tarefa ser concluído com sucesso pelo operador ou equipe em qualquer estágio na operação de um sistema dentro do mínimo tempo exigido (quando a dimensão do tempo é relevante). A análise de confiabilidade humana ( $\mathrm{ACH}$ ) estuda a execução das ações humanas em um determinado sistema, considerando os fatores que influenciam no seu desempenho, os quais comumente evidenciam a incompatibilidade existente entre as limitações humanas e as condições impostas para o trabalho. Exemplos desses fatores incluem restrições de tempo para executar uma atividade, carga de trabalho excessiva, treinamento inadequado do operador, procedimentos mal elaborados, complexidade da tarefa, entre outros.

A maioria dos métodos de $\mathrm{ACH}$ leva em consideração os fatores de desempenho (FDs) através da especificação da probabilidade de erro humano (PEH) como uma função de possíveis valores assumidos por esses fatores. Porém, as relações de dependência existentes entre os FDs não são consideradas (HOLLNAGEL, 1998). Tais relações incluem, por exemplo, a influência que uma carga de trabalho excessiva exerce no estresse de um indivíduo, assim como a influência que a organização exerce na sua motivação. Não considerar essas relações é realizar uma $\mathrm{ACH}$ através de suposições irreais de independência, distanciando-se assim de uma representação apropriada do comportamento humano. Contudo, os métodos de $\mathrm{ACH}$ tradicionais, classificados na literatura como modelos de primeira e segunda geração, realizam essas suposições em grande parte devido à dificuldade encontrada em utilizar árvores de eventos e árvores de falhas para $\mathrm{ACH}$.

No entanto, como será mostrado neste artigo, através de redes Bayesianas (RBs) é possível contabilizar esses efeitos, além de possibilitar a modelagem das ações dos operadores considerando a interação existente entre eles como, por exemplo, a influência de um supervisor no desempenho dos seus subordinados. Este artigo apresenta uma metodologia baseada em RBs para ACH com aplicação na manutenção de linhas de transmissão (LTs). Esta atividade consiste de intervenções em LTs para substituição de cadeias de isoladores. Estes devem resistir às solicitações elétricas e mecânicas que lhes são impostas. Periodicamente, é necessário substituílos, uma vez que estão sujeitos a oxidação, o que compromete suas características mecânicas e elétricas. Esta substituição é realizada por uma equipe de manutenção de LTs.

Assim como em qualquer outra atividade, a substituição de isoladores está sujeita a erros humanos. Porém, erros cometidos aqui, além de exporem eletricistas a riscos, também podem causar interrupções no fornecimento de energia elétrica. Dessa forma, torna-se extremamente importante o desenvolvimento de uma metodologia para $\mathrm{ACH}$ dessa atividade.

O artigo está assim organizado. Na próxima seção, este artigo mostra as principais deficiências dos modelos de $\mathrm{ACH}$ tradicionais, justificando a $\mathrm{ACH}$ via RBs. Na seção seguinte, são apresentadas as vantagens de se utilizar RBs para $\mathrm{ACH}$. Logo após, propõe-se uma metodologia sistemática para $\mathrm{ACH}$. Depois, utiliza-se a metodologia proposta para modelagem das ações humanas em atividades de manutenção de LTs. Por último, avalia-se a confiabilidade humana através de uma análise de curvas de utilidades e o artigo conclui-se em seguida.

\section{ACH estuda a execução das ações humanas em um determinado sistema, considerando os fatores que influenciam no seu desempenho.}

\section{MODELOS DE ACH DE PRIMEIRA E SEGUNDA GERAC̣ÃO}

Os modelos de $\mathrm{ACH}$ apresentados na literatura podem ser classificados em modelos de primeira e modelos de segunda geração.

Os modelos de primeira geração mais citados na literatura podem ser vistos na Tabela 1, onde estão listados com seus respectivos autores e ano de publicação. As colunas mostram outros autores que contribuíram com algumas observações importantes sobre esses modelos (HOLLNAGEL, 1998).

Entre esses modelos, destaca-se a THERP, que é provavelmente o método mais conhecido entre os de primeira geração (HOLLNAGEL, 1998). A metodologia THERP é baseada em árvores de eventos. Cada nó na árvore de eventos corresponde a uma ação em particular e as ramificações representam o erro ou sucesso do operador em executar esta ação. Através do uso do banco de dados fornecido pela THERP é possível estimar as probabilidades de erro e sucesso de cada ação (um nó na árvore de eventos). Posteriormente, as probabilidades são ajustadas com a finalidade de considerar os FDs relevantes para um contexto específico (HOLLNAGEL, 1998). Mediante as dificuldades encontradas em modelar ações humanas via árvores binárias de eventos, tais como representar o contexto em que os eventos ocorrem através de nós na árvore de eventos, este método não considera a dependência entre eventos e entre FDs, o que constitui sua principal deficiência. 
Com o objetivo de superar essa deficiência, surgiram os modelos de ACH de segunda geração. A Tabela 2 apresenta esses modelos.

Dentre estes, destaca-se o CREAM, o qual apresenta uma tentativa de quantificar mais explicitamente a influência de fatores sobre o desempenho dos operários através de uma generalização da árvore de eventos numa classificação policotômica. O CREAM, entretanto, não incorpora explicitamente o tratamento de contextos dinâmicos (KIM, 2001). Agregando-se a esta desvantagem a suposição de independência entre eventos, têm-se as principais deficiências desse modelo.

Percebe-se, portanto, que modelar as causalidades existentes nas ações humanas tornou-se um grande desafio para $\mathrm{ACH}$ e, conseqüentemente, torna-se necessário o desenvolvimento de uma metodologia para $\mathrm{ACH}$ que venha a contornar essas deficiências.

\section{RBs NA ACH}

Diante das críticas aos modelos de $\mathrm{ACH}$ tradicionais surgem as expectativas quanto a métodos futuros. Estas podem ser encontradas em Mosleh e Chang (2004). A seguir apresentam-se algumas das expectativas desses autores e como a utilização de RBs, na opinião dos autores deste artigo, pode contribuir na resolução de cada uma delas [para uma discussão sobre conceitos de RBs recomendam-se Pearl (1988), Korb e Nicholson (2003), Firmino e Droguett (2004) e Menêzes et al. (2005)]:

1) Identificação de erros de maneira contextual e estimação de probabilidades: RBs contextualizam o erro, tanto qualitativamente, através dos causadores presentes vistos através da estrutura gráfica, quanto quantitativamente, através do cálculo das probabilidades condicionais da rede;

2) Melhores modelos causais: RBs são, por definição, estruturas gráficas que representam as relações de causa e efeito entre variáveis;

3) Representação mais realista da natureza dinâmica das interações homem-sistema: RBs permitem representar a dinâmica das interações, através da montagem de cenários na rede, e as relações de causa e efeito pertencentes ao contexto.

4) Capaz de ser aplicada em contextos diferentes: RBs são uma grande ferramenta para analisar diferentes contextos. Por exemplo, monitorar problemas operacionais através de diagnósticos e prognósticos, possibilitando um melhor

Tabela 1: Modelos de 1a geração.

KIRWAN(1994)

GERTMAN \& BLACKMAN (1994)

SPURGIN \& MOIENI(1991)

SWAIN (1989)

HANEY ET AL.(1989)

\begin{tabular}{|c|c|c|c|c|c|c|}
\hline \multicolumn{2}{|l|}{ LUCAS (1988) } & & & & & \\
\hline CM- Confusion Matrix (Potash et al., 1981) & $x$ & $\mathrm{x}$ & $\mathrm{x}$ & & $\mathrm{x}$ & \\
\hline OAT-Operator Action Trre (Wreathall, 1982) & $x$ & $\mathrm{x}$ & $\mathrm{x}$ & $\mathrm{x}$ & & \\
\hline $\begin{array}{l}\text { STAHR-Socio-Technical Assessment of Human Reliability } \\
\text { (Phillips et al., 1983) }\end{array}$ & & $\mathrm{x}$ & $x$ & & $x$ & $\mathrm{x}$ \\
\hline $\begin{array}{l}\text { THERP-Technique of Human Error Rate Prediction (Swain \& } \\
\text { Guttman, 1983) }\end{array}$ & & $\mathrm{x}$ & $\mathrm{x}$ & $\mathrm{x}$ & $\mathrm{x}$ & $\mathrm{x}$ \\
\hline Expert estimation (Comer et al., 1984) & & $\mathrm{x}$ & & $\mathrm{x}$ & $\mathrm{x}$ & $\mathrm{x}$ \\
\hline $\begin{array}{l}\text { SLIM/MAUD-Success Likelihood Index Method/Mult-Atribbute } \\
\text { Utility Decomposition (Embrey et al., 1984) }\end{array}$ & & $\mathrm{x}$ & $\mathrm{x}$ & $\mathrm{x}$ & $\mathrm{x}$ & $\mathrm{x}$ \\
\hline HCR-Human Cognitive Reliability (Hannaman et al., 1984) & & $\mathrm{x}$ & $\mathrm{x}$ & $\mathrm{x}$ & $x$ & $x$ \\
\hline $\begin{array}{l}\text { MAPPS-Maintenance Personnel Performance Simulation } \\
\text { (Siegel et al., 1984] }\end{array}$ & & $x$ & $x$ & & $x$ & $x$ \\
\hline
\end{tabular}

Fonte: HOLLNAGEL, E. Cognitive Reliability and Error Analysis Method. Elsevier Science: England, 1988, p. 124. 
entendimento sobre a relevância dos FDs nos operadores, permitindo assim a providência de medidas que atenuem os seus efeitos. Pode-se também solucionar problemas gerenciais através do conhecimento prévio de fatores decisivos, tais como uma melhor definição das qualidades de um operador na contratação;

5) Melhor calibração com eventos operacionais atuais: através de RBs é possível atualizar o sistema realizando inferências subjetivas e empíricas (recomenda-se Menêzes et al., 2005).

Percebe-se que as características de RBs parecem suprir muitas das expectativas em relação a métodos de $\mathrm{ACH}$ futuros, demonstrando, assim, ser uma boa aproximação na modelagem de erros humanos.

A seguir será apresentada uma metodologia para $\mathrm{ACH}$.

\section{METODOLOGIA PARA A ANÁLISE DE CONFIABILIDADE HUMANA (ACH)}

A metodologia proposta de $\mathrm{ACH}$ está basicamente centrada na identificação e construção de um modelo causal via RB dinâmica das etapas críticas de determinadas ações humanas. Este modelo é então integrado com as RBs que caracterizam as relações causais entre os FDs relevantes para diferentes tipos de erros humanos. A Figura 1 ilustra de forma sistemática as etapas envolvidas nesta metodologia.

Cada uma dessas etapas é descrita a seguir:

Familiarização com o procedimento: esta etapa corresponde à obtenção do conhecimento necessário sobre o procedimento que se deseja modelar. Este conhecimento normalmente é adquirido através de leitura de normas disponíveis e observações do procedimento na prática. Nesta etapa é importante observar também o contexto, ou seja, as condições ou circunstâncias nas quais o procedimento ocorre. No contexto, são identificados os fatores de desempenho (FDs), comumente chamados de performance shaping factors (SWAIN; GUTTMANN,1983).

Construção da HTA: as informações adquiridas na etapa anterior, relacionadas ao procedimento, são descritas e organizadas através da HTA (Hierarchical Task analysis), que é um método sistemático usado para descrever e organizar as tarefas que deverão ser executadas no decorrer da realização de um trabalho (KIRWAN; AINSWORTH, 1992).

Tabela 2: Modelos de 2a geração.

\begin{tabular}{|c|c|}
\hline MODELOS DE ACH DE २а GERAÇÃO & REFERÊNCIAS \\
\hline Cognitive Environment Simulator (CES) & Woods et al. (1988), Hollnagel (1998) \\
\hline Intention Event tree System (INTENT) & Gertman et al. (1990; 1992), Hollnagel [1998) \\
\hline Cognitive Event Tree System (COGENT) & Gertman et al. (1992; 1993), Hollnagel (1998) \\
\hline $\begin{array}{l}\text { EPRI Project on Methods for Addressing Human in Safety } \\
\text { Analysis }\end{array}$ & Parry \& Mosleh (1995], Hollnagel [1998] \\
\hline Human Interaction Timeline (HITLINE) & Macwan \& Mosleh (1994], Hollnagel [1998] \\
\hline A Technique for Human Error Analysis [ATHEANA] & Cooper et al. (1996], Hollnagel [1998] \\
\hline Cognitive Reliability and Error Analysis Method (CREAM) & Hollnagel [1998], Kim [2001] \\
\hline
\end{tabular}

Figura 1: Fluxograma da metodologia proposta.

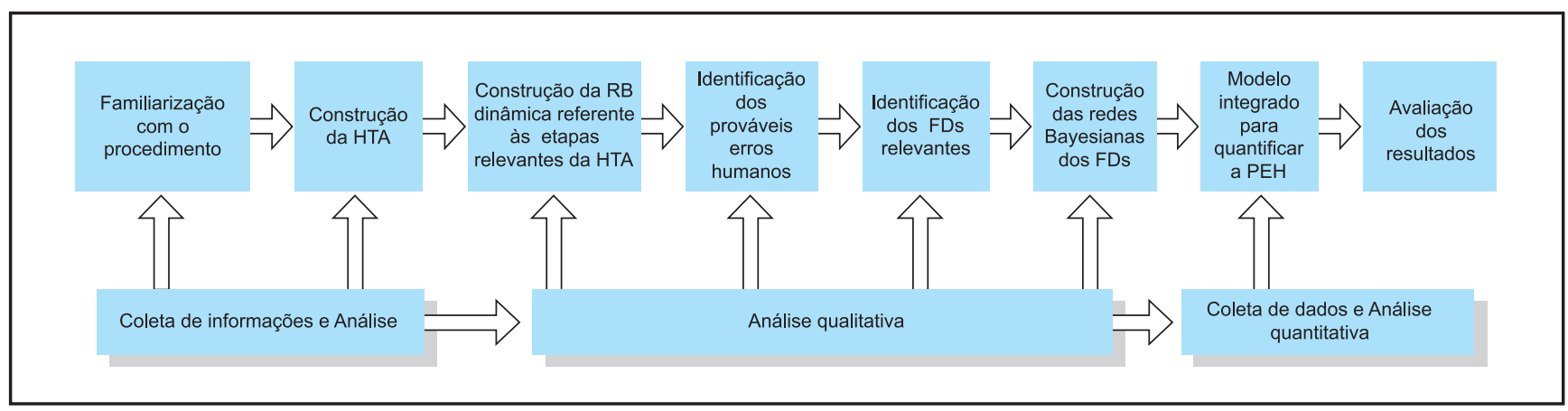


As etapas mencionadas acima compõem a fase inicial de um estudo de $\mathrm{ACH}$, isto é, coleta de informações e análise. As próximas etapas correspondem à análise qualitativa das informações recebidas através da modelagem das ações humanas via RBs.

Construção da $R B$ dinâmica referente às etapas relevantes da HTA: nesta etapa são identificadas as etapas críticas da HTA em termos de riscos para o sistema. A partir dessas etapas é construída a RB dinâmica da tarefa, a qual representa as ações humanas através de cenários distintos e seqüenciais, e permite uma visualização da interação existente entre estas ações. tenção de LTs utilizando a metodologia que foi proposta nesta seção.

\section{ACH DE UMA EQUIPE DE MANUTENCÃO DE LINHAS DE TRANSMISSÃO (LTs)}

A atividade modelada aqui corresponde a intervenções em LTs energizadas para a troca de cadeias de isoladores, cujo objetivo é substituir isoladores oxidados por isoladores novos. Para tanto, realiza-se a montagem de um retângulo de forças na estrutura (ou torre), cuja função é sustentar o peso da LT enquanto os eletricistas realizam a troca. A maioria das estruturas encontra-se em locais ermos, longe dos centros urbanos, uma vez que têm a função de sustentar linhas que transportam energia elétrica entre os centros de produção e subestações. Nestes locais, os eletricistas estão expostos a condições que podem alterar o desempenho de suas tarefas, tais como temperatura e umidade, as quais podem comprometer as

Identificação dos prováveis erros humanos: através dos cenários constituintes da RB da tarefa e do conhecimento adquirido na fase inicial, identificam-se os prováveis erros de cada indivíduo, bem como as conseqüências associadas. Esta identificação possibilita um melhor entendimento do comportamento das pessoas envolvidas, permitindo que pelos prováveis erros humanos relatados sejam conhecidas as suas prováveis causas.

Identificação dos FDs relevantes: uma vez identificados os prováveis erros humanos, identificam-se os prováveis fatores responsáveis por tais erros. Nesta etapa serão identificados os FDs relevantes para cada indivíduo envolvido na tarefa.

Construção das RBs dos FDs: nesta etapa, são identificadas as relações de causa e efeito existentes entre os FDs identificados na etapa anterior. Posteriormente, é construída uma RB para cada indivíduo de acordo com a sua função no sistema.

As próximas etapas correspondem à coleta de dados e análise quantitativa através da modelagem das ações humanas via RBs.

Modelo integrado para quantificar a probabilidade de erro humano (PEH): nesta etapa é realizada a integração das RBs dos FDs à rede Bayesiana da tarefa. Então, cada indivíduo representado através de um nó na $\mathrm{RB}$ da tarefa terá a sua RB referente aos seus FDs relevantes.

Avaliação dos resultados: após a modelagem dos dados, inicia-se o processo de avaliação dos resultados. RBs proporcionam uma análise mais detalhada dos resultados, pois possibilitam verificar a influência de evidências empíricas e subjetivas na PEH.

A seguir apresenta-se a $\mathrm{ACH}$ de uma equipe de manucaracterísticas isolantes dos bastões utilizados para suporte da instalação e manuseio pelos eletricistas das partes energizadas. Pode-se citar ainda: luminosidade, ruído, presença de insetos no local, grau de limpeza da faixa de servidão, isto é, a conservação da faixa para facilitar o acesso dos eletricistas à estrutura, entre outras.

A equipe é composta por sete eletricistas, sendo um deles o encarregado. Este tem a função de liderar e monitorar a equipe. Para a troca da cadeia, os eletricistas assumem funções diferentes. Três eletricistas, geralmente os mais experientes, sobem na estrutura para realizar a troca. A Figura 2 (a) mostra o eletricista de topo (ET), cuja função principal e montar/desmontar o retângulo de forças, o eletricista de montagem (EM), cuja principal função é retirar/colocar isoladores na estrutura, e o eletricista de apoio (EA), cuja tarefa consiste na retirada e colocação dos isoladores na linha de mão. Os outros três eletricistas ficam na faixa de servidão, próximos à estrutura, exibidos na Figura 2 (b). Estes dão suporte aos eletricistas que estão na estrutura, isto é, seguram a linha de mão, artifício utilizado para içamento de equipamentos, ferramentas e isoladores à estrutura. Atribui-se a estes a função de eletricistas auxiliares (EAUX).

A descrição da tarefa foi realizada através da HTA. Este método foi selecionado entre tantos outros por ser capaz de organizar a tarefa em uma escala de atividades, tratando cada uma delas com o nível de detalhamento desejado, e também por possibilitar uma melhor visualização de como as atividades interagem com o trabalho como um todo. A Figura 3 apresenta a HTA no primeiro nível. Para a descrição da substituição de cadeias de isoladores, algumas etapas ou planos foram detalhados até o quarto nível, porém não mostrados aqui por questão de brevidade. 
Os planos 3, 4 e 5 da HTA foram considerados os mais relevantes em termos de importância e criticalidade para a confiabilidade e segurança dos eletricistas envolvidos. Evidentemente, um bom desempenho dos eletricistas com exceção de falhas de equipamentos e inadequação de ferramentas conduzem o sistema ao sucesso.

A montagem do retângulo de forças (plano 3 ) tem a finalidade de sustentar o peso da linha, enquanto os eletricistas realizam a substituição dos isoladores. Após instalado, realiza-se o tensionamento do retângulo de forças, isto é, a transferência do peso da linha para o retângulo de forças. A troca da cadeia de isoladores (plano 4) pode ser vista como a etapa da atividade em que há uma maior interação entre os eletricistas. É nesta etapa que os eletricistas retiram a cadeia de isoladores e colocam a nova cadeia de isoladores.
Conseqüentemente, a movimentação dos bastões universais constitui a relevância desta atividade, pois existem distâncias mínimas de segurança entre os trabalhos de manutenção e as partes energizadas, as quais precisam ser obedecidas de forma a garantir que não haja descargas elétricas de potência. $\mathrm{Na}$ desmontagem do retângulo de forças (plano 5), realiza-se o destensionamento do mesmo, isto é, a transferência do peso da linha para a nova cadeia de isoladores. Portanto, é imprescindível que a cadeia tenha sido colocada corretamente, isto é, bater todos os contrapinos, realizar o engate do concha-garfo e verificar se a nova cadeia está fixa (MENÊZES; DROGUETT, 2005).

Os planos comentados constituem as etapas relevantes para a construção da RB da tarefa, a qual será abordada a seguir.

Figura 2: Disposição dos eletricistas durante a troca.

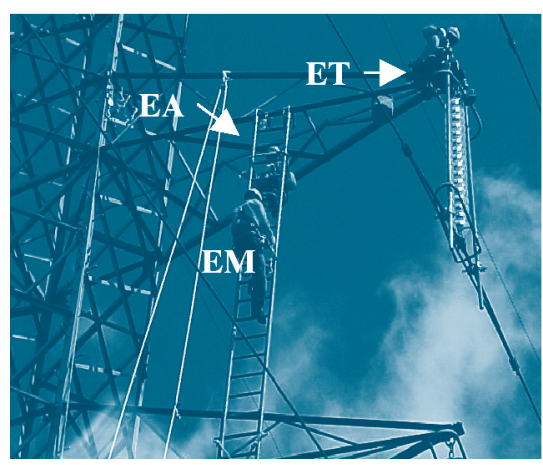

[a]

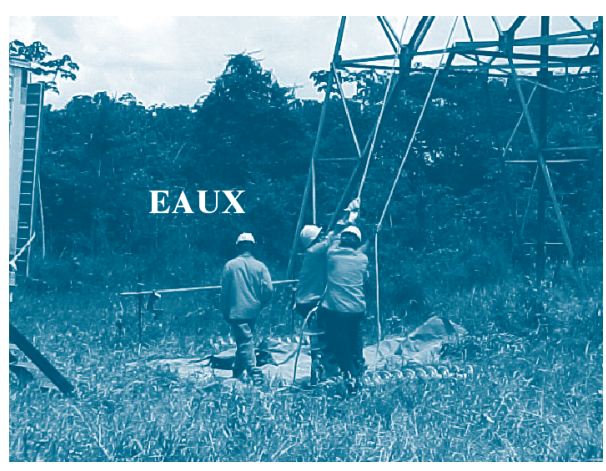

(b)

Figura 3: HTA no primeiro nível de detalhamento.

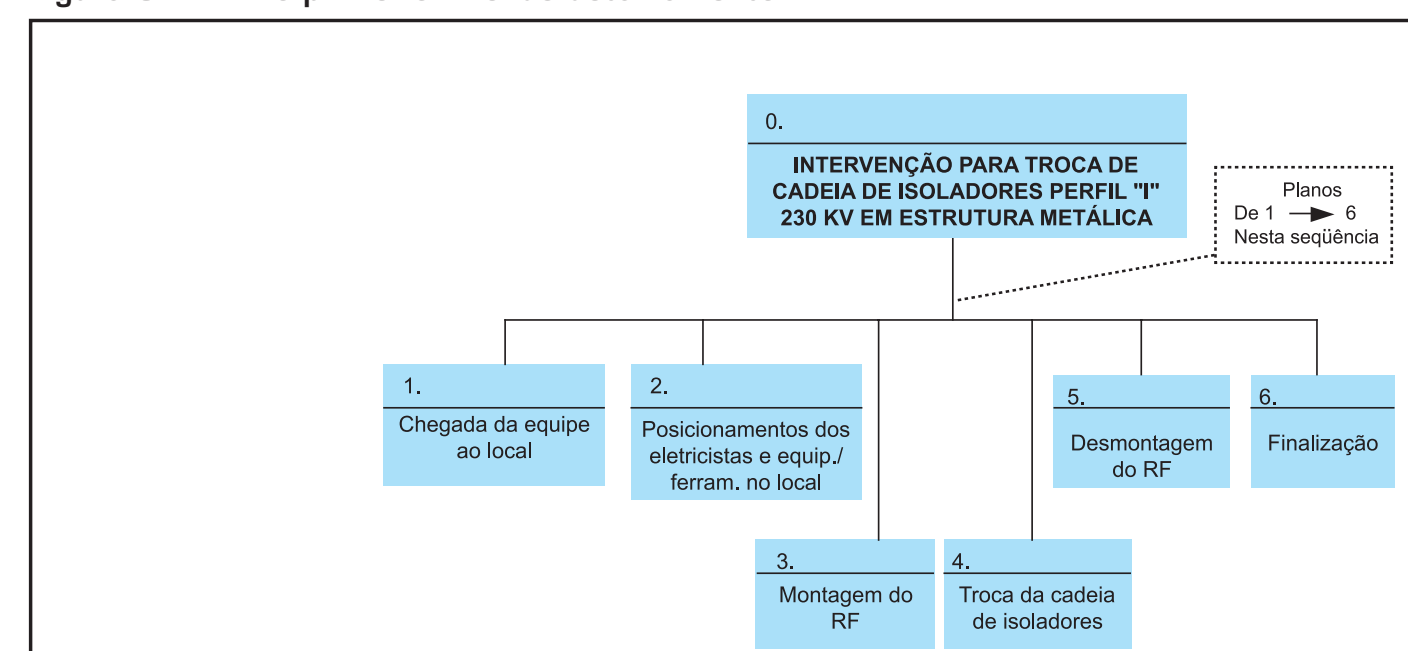




\section{Rede Bayesiana da tarefa}

Baseado nos planos (ou etapas) comentados na seção anterior foi construída a $\mathrm{RB}$ da tarefa, a qual pode ser vista na Figura 4, onde:

$\mathrm{Ci}: \mathrm{C}_{0} \ldots \mathrm{C}_{6}$

EAi: Eletricista de apoio no cenário i;

ETi: Eletricista de topo no cenário i;

EMi: Eletricista de montagem no cenário i;

E*i: $(\mathrm{ET}+\mathrm{EM})$ no cenário i;

EAUXi: Eletricistas auxiliares no cenário i;

EEi: Eletricista encarregado no cenário i;

C5: (EM + EA) no cenário 5.

Esta rede apresenta seqüencialmente sete cenários críticos, os quais possibilitam a representação dinâmica da tarefa. Estes cenários correspondem à seguinte seqüência de ações:

Cenário 0: Tensionamento do retângulo de forças;

Cenário 1: Retirada dos contrapinos;

Cenário 2: Retirada da cadeia velha de isoladores;

Cenário 3: Subida/descida de isoladores;

Cenário 4: Colocação da cadeia de isoladores;

Cenário 5: Engate do concha-garfo e verificação da cadeia;

Cenário 6: Destensionamento do retângulo de forças.

As variáveis aleatórias são dicotômicas e representam o erro ou o sucesso dos eletricistas envolvidos na atividade, enquanto os arcos tracejados representam as relações causais existentes entre as mesmas, isto é, a interação existente entre os eletricistas. Por exemplo, a influência que o EE tem sobre os outros eletricistas.

Tendo-se caracterizado as etapas do procedimento de manutenção e identificado os cenários críticos, pode-se agora identificar os prováveis erros humanos de cada eletricista envolvido na execução da tarefa, assim como conseqüências associadas. Note que esta análise é realizada para cada um dos cenários da Figura 4, e tem por objetivo apresentar detalhadamente o comportamento dos eletricistas, possibilitando um melhor entendimento de cada variável da RB da Figura 4 na ACH. As Tabelas de 3 a 9 a seguir apresentam os prováveis erros e conseqüências, bem como uma melhor descrição dos cenários da Figura 4.

Agora que já se sabe como os erros humanos são cometidos e quais as dimensões de seus efeitos, é necessário identificar quais são as prováveis causas, ou seja, quais são os FDs e como eles impactam no desempenho dos eletricistas durante a execução da atividade. Estes FDs dependem do contexto no qual os eletricistas realizam a tarefa e serão apresentados na próxima seção.

\section{Relações de causa e efeito entre os FDs}

Os FDs são todos os fatores que de alguma forma afetam a confiabilidade humana e conseqüentemente auxiliam na determinação da PEH (SWAIN; GUTTMANN, 1983). Os FDs foram identificados através das observações do procedimento de intervenção de LTs na prática e de eduções qualitativas de especialistas.

Figura 4: Rede Bayesiana da tarefa.

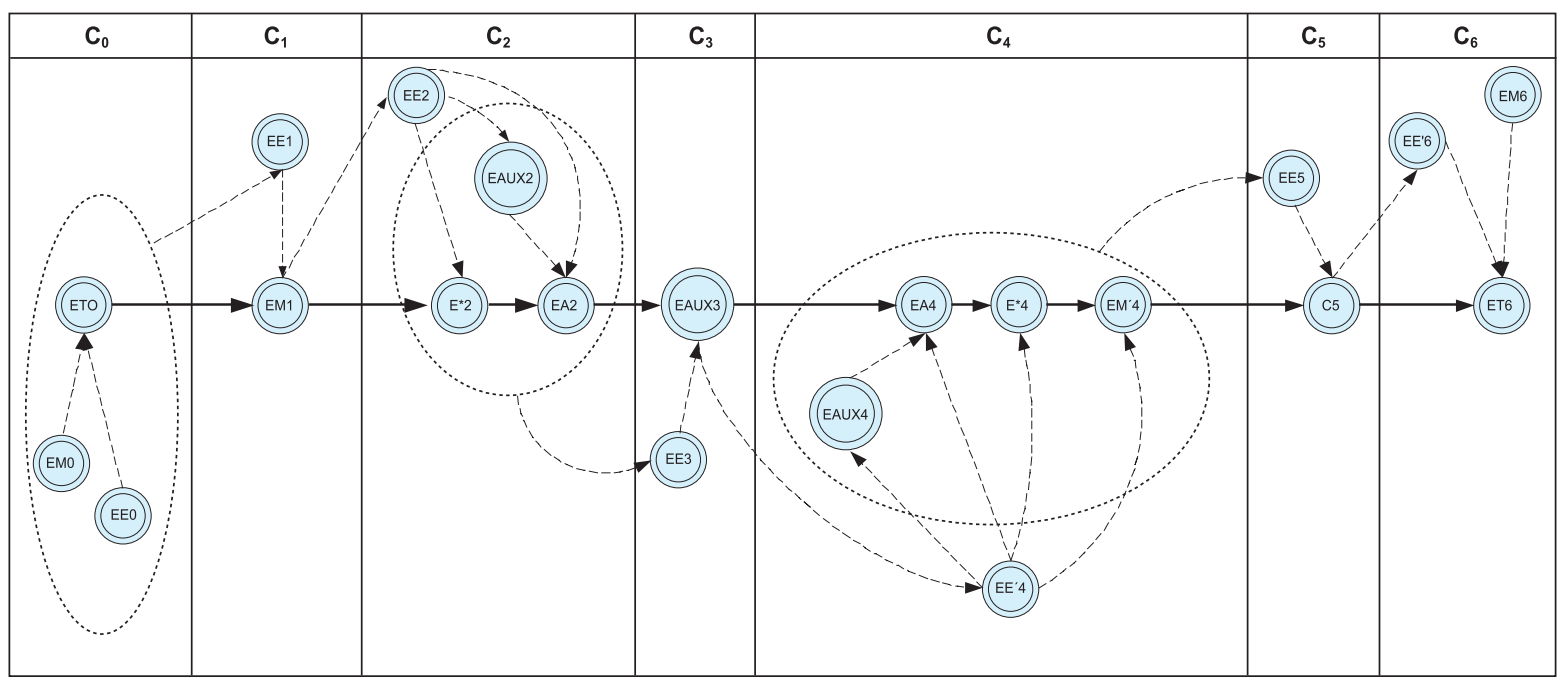


Estes fatores não agem de maneira isolada, pois existem relações de causa e efeito entre eles, tais como o efeito da fadiga na atenção e vigilância de um indivíduo, a influência da motivação no desempenho humano, entre outras. Estas não foram consideradas nos modelos de $\mathrm{ACH}$ tradicionais. Entretanto, alguns avanços têm sido atingidos. Por exemplo, Chang e Mosleh (1999), ao tentarem modelar as ações hu- manas de um operador de uma sala de controle em um planta de energia nuclear, elaboraram um diagrama de influência, IDAC (Information, Decision, and action in crew context), o qual apresenta as relações de causa e efeito entre a maioria dos FDs. Apesar de esse diagrama ter trazido grandes contribuições para $\mathrm{ACH}$, algumas relações não foram consideradas, tais como:

Tabela 3: Análise do cenário 0.

\begin{tabular}{|c|c|c|c|c|c|}
\hline CENÁRIO O & $\begin{array}{l}\text { PESSOAL } \\
\text { ENVOLVIDO }\end{array}$ & $\begin{array}{l}\text { LOCALIZAÇÃO DO } \\
\text { ENVOLVIDO }\end{array}$ & AÇÃO HUMANA & ERRO HUMANO & CONSEQÜÊNCIA \\
\hline \multirow{4}{*}{$\begin{array}{l}\text { Tensionamento } \\
\text { do retângulo } \\
\text { de força }\end{array}$} & \multirow{3}{*}{$\begin{array}{l}\text { Eletricista de } \\
\text { Topo }\end{array}$} & \multirow{3}{*}{ Na porta da mísula } & $\begin{array}{l}\text { Posicionar as traves } \\
\text { da chave catraca na } \\
\text { posição de aperto }\end{array}$ & \multirow{3}{*}{$\begin{array}{l}\text { Tensionar } \\
\text { mal, causando } \\
\text { desbalan- } \\
\text { ceamento do } \\
\text { retângulo de } \\
\text { forças }\end{array}$} & \multirow{3}{*}{$\begin{array}{l}\text { Quebra do jugo } \\
\text { e queda da linha } \\
\text { de transmissão }\end{array}$} \\
\hline & & & $\begin{array}{l}\text { Encaixar as chaves } \\
\text { nos munhões e sobre } \\
\text { elas, as porcas de } \\
\text { espera }\end{array}$ & & \\
\hline & & & $\begin{array}{l}\text { Transferir a tensão } \\
\text { mecânica da cadeia } \\
\text { para os bastões } \\
\text { tensores do retângulo } \\
\text { de força }\end{array}$ & & \\
\hline & $\begin{array}{l}\text { Eletricista de } \\
\text { montagem }\end{array}$ & Na escada & $\begin{array}{l}\text { Indicar o instante } \\
\text { de parada do } \\
\text { tensionamento }\end{array}$ & Indicar errado & $\begin{array}{l}\text { Atraso na } \\
\text { atividade }\end{array}$ \\
\hline & $\begin{array}{l}\text { Eletricista } \\
\text { Encarregado }\end{array}$ & $\begin{array}{l}\text { Na faixa de } \\
\text { servidão }\end{array}$ & Monitorar a atividade & $\begin{array}{l}\text { Não observar } \\
\text { a atividade de } \\
\text { forma adequada }\end{array}$ & $\begin{array}{l}\text { Ocorrem erros } \\
\text { que poderiam } \\
\text { ser corrigidos e } \\
\text { evitados }\end{array}$ \\
\hline
\end{tabular}

Tabela 4: Análise do cenário 1.

\begin{tabular}{|c|c|c|c|c|c|}
\hline CENÁRIO 1 & $\begin{array}{l}\text { PESSOAL } \\
\text { ENVOLVIDO }\end{array}$ & $\begin{array}{l}\text { LOCALIZAÇÃO DO } \\
\text { ENVOLVIDO }\end{array}$ & AÇÃO HUMANA & ERRO HUMANO & CONSEQÜÊNCIA \\
\hline \multirow{3}{*}{$\begin{array}{l}\text { Retirada dos } \\
\text { contrapinos }\end{array}$} & \multirow{3}{*}{$\begin{array}{l}\text { Eletricista de } \\
\text { Montagem }\end{array}$} & \multirow{3}{*}{ Na escada } & $\begin{array}{l}\text { Desatrelar a cadeia } \\
\text { de isoladores do } \\
\text { engate do concha } \\
\text { olhal }\end{array}$ & \multirow{3}{*}{$\begin{array}{l}\text { Não retirar } \\
\text { todos os } \\
\text { contra-pinos } \\
\text { necessários }\end{array}$} & \multirow{3}{*}{$\begin{array}{l}\text { Atraso na } \\
\text { atividade }\end{array}$} \\
\hline & & & $\begin{array}{l}\text { Retirar os contra- } \\
\text { pinos de três em três } \\
\text { isoladores a partir do } \\
\text { concha olhal }\end{array}$ & & \\
\hline & & & Monitorar a atividade & & \\
\hline & $\begin{array}{l}\text { Eletricista } \\
\text { Encarregado }\end{array}$ & $\begin{array}{l}\text { Na faixa de } \\
\text { servidão }\end{array}$ & Monitorar a atividade & $\begin{array}{l}\text { Não observar } \\
\text { a atividade de } \\
\text { forma adequada }\end{array}$ & $\begin{array}{l}\text { Ocorrem erros } \\
\text { que poderiam } \\
\text { ser corrigidos e } \\
\text { evitados }\end{array}$ \\
\hline
\end{tabular}


Tabela 5: Análise do cenário 2.

\begin{tabular}{|c|c|c|c|c|c|}
\hline GENÁRIO ? & $\begin{array}{l}\text { PESSOAL } \\
\text { ENVOLVIDO }\end{array}$ & $\begin{array}{c}\text { LOCALIZAÇÃO DO } \\
\text { ENVOLVIDO }\end{array}$ & AÇÃO HUMANA & ERRO HUMANO & CONSEQÜÊNGIA \\
\hline \multirow{7}{*}{$\begin{array}{l}\text { Retirada da } \\
\text { cadeia de } \\
\text { isoladores }\end{array}$} & \multirow{2}{*}{$\begin{array}{l}\text { Eletricista de } \\
\text { Montagem }\end{array}$} & \multirow{2}{*}{$\mathrm{Na}$ escada } & \multirow{2}{*}{$\begin{array}{l}\text { Retirar os isoladores } \\
\text { juntamente com o } \\
\text { Eletricista de Topo }\end{array}$} & $\begin{array}{l}\text { Deixar cair } \\
\text { isoladores } \\
\text { na faixa de } \\
\text { servidão }\end{array}$ & $\begin{array}{l}\text { Possibilidade } \\
\text { de machucar } \\
\text { eletricistas que } \\
\text { estão na faixa de } \\
\text { servidão }\end{array}$ \\
\hline & & & & $\begin{array}{l}\text { Movimentos } \\
\text { fora de } \\
\text { sincronia }\end{array}$ & $\begin{array}{l}\text { Sobrecarregar } \\
\text { apenas um } \\
\text { eletricista } \\
\text { envolvido na } \\
\text { operação }\end{array}$ \\
\hline & $\begin{array}{l}\text { Eletricista de } \\
\text { Topo }\end{array}$ & No meio da mísula & $\begin{array}{l}\text { Ajudar o Eletricista de } \\
\text { Montagem a suportar } \\
\text { o peso dos isoladores }\end{array}$ & $\begin{array}{l}\text { Idem Eletricista } \\
\text { de Montagem }\end{array}$ & $\begin{array}{l}\text { Idem Eletricista } \\
\text { de Montagem }\end{array}$ \\
\hline & \multirow[t]{2}{*}{$\begin{array}{l}\text { Eletricista de } \\
\text { apoio }\end{array}$} & \multirow[t]{2}{*}{ Na escada } & \multirow[t]{2}{*}{$\begin{array}{l}\text { Retirar os isoladores } \\
\text { do bastão e colocá-los } \\
\text { nas linhas de mão }\end{array}$} & $\begin{array}{l}\text { Deixar cair } \\
\text { isoladores } \\
\text { na faixa de } \\
\text { servidão }\end{array}$ & $\begin{array}{l}\text { Possibilidade } \\
\text { de machucar } \\
\text { eletricistas que } \\
\text { estão na faixa de } \\
\text { servidão }\end{array}$ \\
\hline & & & & $\begin{array}{l}\text { Movimentos } \\
\text { fora de } \\
\text { sincronia }\end{array}$ & $\begin{array}{l}\text { Atraso na } \\
\text { atividade }\end{array}$ \\
\hline & $\begin{array}{l}\text { Eletricistas } \\
\text { Auxiliares }\end{array}$ & $\begin{array}{l}\text { Na faixa de } \\
\text { servidão }\end{array}$ & $\begin{array}{l}\text { Segurar a linha de } \\
\text { mão }\end{array}$ & $\begin{array}{l}\text { Permitir que } \\
\text { a linha de mão } \\
\text { balance e/ou } \\
\text { aproximá-la da } \\
\text { operação }\end{array}$ & $\begin{array}{l}\text { Comprometer } \\
\text { o trabalho do } \\
\text { Eletricista de } \\
\text { Apoio }\end{array}$ \\
\hline & $\begin{array}{l}\text { Eletricista } \\
\text { Encarregado }\end{array}$ & $\begin{array}{l}\text { Na faixa de } \\
\text { servidão }\end{array}$ & Monitorar a atividade & $\begin{array}{l}\text { Não observar } \\
\text { a atividade de } \\
\text { forma adequada }\end{array}$ & $\begin{array}{l}\text { Ocorrem erros } \\
\text { que poderiam } \\
\text { ser corrigidos e } \\
\text { evitados }\end{array}$ \\
\hline
\end{tabular}

Tabela 6: Análise do cenário 3.

\begin{tabular}{|c|c|c|c|c|c|}
\hline GENÁRIO 3 & $\begin{array}{l}\text { PESSOAL } \\
\text { ENVOLVIDO }\end{array}$ & $\begin{array}{l}\text { LOCALIZAÇÃO DO } \\
\text { ENVOLVIDO }\end{array}$ & AÇÃO HUMANA & ERRO HUMANO & CONSEQÜÊNGIA \\
\hline \multirow{3}{*}{$\begin{array}{l}\text { Subida/descida } \\
\text { de isoladores }\end{array}$} & \multirow[b]{2}{*}{$\begin{array}{l}\text { Eletricistas } \\
\text { Auxiliares }\end{array}$} & \multirow[b]{2}{*}{$\begin{array}{l}\text { Na faixa de } \\
\text { servidão }\end{array}$} & \multirow{2}{*}{$\begin{array}{l}\text { Através da linha } \\
\text { de mão conduzem } \\
\text { simultaneamente a } \\
\text { subida da cadeia nova } \\
\text { e descida da cadeia } \\
\text { velha de isoladores }\end{array}$} & $\begin{array}{l}\text { Permitir que } \\
\text { haja colisão dos } \\
\text { isoladores com } \\
\text { a estrutura }\end{array}$ & $\begin{array}{l}\text { Danificar } \\
\text { isoladores novos }\end{array}$ \\
\hline & & & & $\begin{array}{l}\text { Deixar cair } \\
\text { isoladores } \\
\text { na faixa de } \\
\text { servidão }\end{array}$ & $\begin{array}{l}\text { Possibilidade de } \\
\text { se machucarem } \\
\text { como também } \\
\text { machucar o } \\
\text { Eletricista } \\
\text { Encarregado }\end{array}$ \\
\hline & $\begin{array}{l}\text { Eletricista } \\
\text { Encarregado }\end{array}$ & $\begin{array}{l}\text { Na faixa de } \\
\text { servidão }\end{array}$ & Monitorar a atividade & $\begin{array}{l}\text { Não observar } \\
\text { a atividade de } \\
\text { forma adequada }\end{array}$ & $\begin{array}{l}\text { Ocorrem erros } \\
\text { que poderiam } \\
\text { ser corrigidos e } \\
\text { evitados }\end{array}$ \\
\hline
\end{tabular}


I) Relação de interdependência entre os fatores fisiológicos: percebe-se, por exemplo, que o débito do sono poderá causar fadiga. Assim como um condicionamento físico inadequado poderá causar desconforto no momento da execução da tarefa e conseqüentemente causar provável fadiga;

II) Relação de interdependência entre os fatores da informação memorizada (IM): a IM reúne o armazenamento de toda informação e habilidade motora desenvolvida durante o treinamento e a prática da atividade de manutenção de LTs. Nestes fatores, observa-se uma relação de interdependência como, por exemplo, através do treinamento e da prática, os eletricistas conseguem desenvolver suas habilidades para executarem a tarefa com maior segurança e confiança;
III) Relação de interdependência entre os fatores externos: estes fatores incluem os fatores pertencentes à organização, à qualidade do ambiente e à relacionados a equipe. Dessa forma, percebe-se, por exemplo, que a política da empresa poderá influenciar alguns fatores, tais como design dos equipamentos utilizados pelos eletricistas, procedimentos de manutenção de LTs, limpeza da faixa de servidão, entre outros. A comunicação entre os eletricistas também poderá estar comprometida pelo ruído existente no ambiente;

IV) Relação de dependência entre os fatores fisiológicos e a informação memorizada: percebe-se também que alguns fatores fisiológicos influenciam na informação

Tabela 7: Análise do cenário 4.

\begin{tabular}{|c|c|c|c|c|c|}
\hline GENÁRIO ? & $\begin{array}{l}\text { PESSOAL } \\
\text { ENVOLVIDO }\end{array}$ & $\begin{array}{c}\text { LOCALIZAÇÃO DO } \\
\text { ENVOLVIDO }\end{array}$ & AÇÃO HUMANA & ERRO HUMANO & CONSEQÜÊNCIA \\
\hline \multirow{8}{*}{$\begin{array}{l}\text { Colocação } \\
\text { da cadeia de } \\
\text { isoladores }\end{array}$} & \multirow{3}{*}{$\begin{array}{l}\text { Eletricista de } \\
\text { Montagem }\end{array}$} & \multirow{3}{*}{ Na escada } & \multirow{2}{*}{$\begin{array}{l}\text { Colocar os isoladores } \\
\text { novos juntamente } \\
\text { com o Eletricista de } \\
\text { Topo }\end{array}$} & $\begin{array}{l}\text { Deixar cair } \\
\text { isoladores } \\
\text { na faixa de } \\
\text { servidão }\end{array}$ & $\begin{array}{l}\text { Possibilidade } \\
\text { de machucar } \\
\text { eletricistas que } \\
\text { estão na faixa de } \\
\text { servidão }\end{array}$ \\
\hline & & & & $\begin{array}{l}\text { Movimentos } \\
\text { fora de } \\
\text { sincronia }\end{array}$ & $\begin{array}{l}\text { Sobrecarregar } \\
\text { apenas um } \\
\text { eletricista } \\
\text { envolvido na } \\
\text { operação }\end{array}$ \\
\hline & & & $\begin{array}{l}\text { Realizar a pinagem } \\
\text { a cada grupo de } \\
\text { isoladores colocados }\end{array}$ & $\begin{array}{l}\text { Não bater todos } \\
\text { os contrapinos }\end{array}$ & Cadeia instável \\
\hline & $\begin{array}{l}\text { Eletricista de } \\
\text { Topo }\end{array}$ & No meio da mísula & $\begin{array}{l}\text { Colocar os isoladores } \\
\text { novos juntamente } \\
\text { com o Eletricista de } \\
\text { Montagem } \\
\end{array}$ & $\begin{array}{l}\text { Idem Eletricista } \\
\text { de Montagem }\end{array}$ & $\begin{array}{l}\text { Idem Eletricista } \\
\text { de Montagem }\end{array}$ \\
\hline & \multirow[t]{2}{*}{$\begin{array}{l}\text { Eletricista de } \\
\text { Apoio }\end{array}$} & \multirow[t]{2}{*}{ Na escada } & \multirow{2}{*}{$\begin{array}{l}\text { Retirar os isoladores } \\
\text { do bastão e colocá-los } \\
\text { na linha de mão }\end{array}$} & $\begin{array}{l}\text { Deixar cair } \\
\text { isoladores } \\
\text { na faixa de } \\
\text { servidão }\end{array}$ & $\begin{array}{l}\text { Possibilidade } \\
\text { de machucar } \\
\text { eletricistas que } \\
\text { estão na faixa de } \\
\text { servidão }\end{array}$ \\
\hline & & & & $\begin{array}{l}\text { Movimentos } \\
\text { fora de } \\
\text { sincronia }\end{array}$ & $\begin{array}{l}\text { Atraso na } \\
\text { atividade }\end{array}$ \\
\hline & $\begin{array}{l}\text { Eletricistas } \\
\text { Auxiliares }\end{array}$ & $\begin{array}{l}\text { Na faixa de } \\
\text { servidão }\end{array}$ & $\begin{array}{l}\text { Segurar a linha de } \\
\text { mão }\end{array}$ & $\begin{array}{l}\text { Permitir que } \\
\text { a linha de mão } \\
\text { balance e/ou } \\
\text { aproximá-la da } \\
\text { operação }\end{array}$ & $\begin{array}{l}\text { Comprometer } \\
\text { o trabalho do } \\
\text { Eletricista de } \\
\text { Apoio }\end{array}$ \\
\hline & $\begin{array}{l}\text { Eletricista } \\
\text { Encarregado }\end{array}$ & $\begin{array}{l}\text { Na faixa de } \\
\text { servidão }\end{array}$ & Monitorar a atividade & $\begin{array}{l}\text { Não observar } \\
\text { a atividade de } \\
\text { forma adequada }\end{array}$ & $\begin{array}{l}\text { Ocorrem erros } \\
\text { que poderiam } \\
\text { ser corrigidos e } \\
\text { evitados }\end{array}$ \\
\hline
\end{tabular}


Tabela 8: Análise do cenário 5.

\begin{tabular}{|c|c|c|c|c|c|}
\hline GENÁRIO 5 & $\begin{array}{l}\text { PESSOAL } \\
\text { ENVOLVIDO }\end{array}$ & $\begin{array}{c}\text { LOCALIZAÇÃO DO } \\
\text { ENVOLVIDO }\end{array}$ & AÇÃO HUMANO & ERRO HUMANO & CONSEQÜÊNGIA \\
\hline \multirow{5}{*}{$\begin{array}{l}\text { Engate do } \\
\text { Concha-garfo e } \\
\text { verificação da } \\
\text { cadeia }\end{array}$} & \multirow[t]{2}{*}{$\begin{array}{l}\text { Eletricista de } \\
\text { Montagem }\end{array}$} & \multirow[t]{2}{*}{ Na escada } & $\begin{array}{l}\text { Realizar o engate } \\
\text { do concha-garfo } \\
\text { juntamente com o } \\
\text { Eletricista de Apoio }\end{array}$ & & \\
\hline & & & $\begin{array}{l}\text { Verificar se a cadeia } \\
\text { está fixa }\end{array}$ & Não verificar & Cadeia instável \\
\hline & \multirow[t]{2}{*}{$\begin{array}{l}\text { Eletricista de } \\
\text { Apoio }\end{array}$} & \multirow[t]{2}{*}{ Na escada } & \multirow[t]{2}{*}{$\begin{array}{l}\text { Evitar o balanço da } \\
\text { cadeia, enquanto } \\
\text { o Eletricista de } \\
\text { Montagem realiza seu } \\
\text { trabalho }\end{array}$} & \multirow[t]{2}{*}{$\begin{array}{l}\text { Permitir que a } \\
\text { cadeia balance }\end{array}$} & $\begin{array}{l}\text { O Eletricista } \\
\text { de Montagem } \\
\text { apresentará } \\
\text { dificuldade na } \\
\text { realização do seu } \\
\text { trabalho }\end{array}$ \\
\hline & & & & & $\begin{array}{l}\text { Atraso na } \\
\text { atividade }\end{array}$ \\
\hline & $\begin{array}{l}\text { Eletricista } \\
\text { Encarregado }\end{array}$ & $\begin{array}{l}\text { Na faixa de } \\
\text { servidão }\end{array}$ & Monitorar a atividade & $\begin{array}{l}\text { Não observar } \\
\text { a atividade de } \\
\text { forma adequada }\end{array}$ & $\begin{array}{l}\text { Ocorrem erros } \\
\text { que poderiam } \\
\text { ser corrigidos e } \\
\text { evitados }\end{array}$ \\
\hline
\end{tabular}

Tabela 9: Análise do cenário 6.

\begin{tabular}{|c|c|c|c|c|c|}
\hline CENÁRIO 6 & $\begin{array}{l}\text { PESSOAL } \\
\text { ENVOLVIDO }\end{array}$ & $\begin{array}{l}\text { LOCALIZAÇÃO DO } \\
\text { ENVOLVIDO }\end{array}$ & AÇÃO HUMANA & ERRO HUMANO & CONSEQÜÊNCIA \\
\hline \multirow{4}{*}{$\begin{array}{l}\text { Destensio- } \\
\text { namento e } \\
\text { desmontagem } \\
\text { do retângulo } \\
\text { de força }\end{array}$} & \multirow{2}{*}{$\begin{array}{l}\text { Eletricista de } \\
\text { Topo }\end{array}$} & \multirow[b]{2}{*}{ Na ponta da mísula } & $\begin{array}{l}\text { Tranferir a tensão } \\
\text { mecânica do retângulo } \\
\text { de força para a cadeia } \\
\text { de isoladores }\end{array}$ & & \\
\hline & & & $\begin{array}{l}\text { Desmontar o } \\
\text { retângulo de força }\end{array}$ & $\begin{array}{l}\text { Evidência de } \\
\text { erros cometidos } \\
\text { em atividades } \\
\text { antecedentes }\end{array}$ & $\begin{array}{l}\text { Queda de linha } \\
\text { Proveniente } \\
\text { da pinagem } \\
\text { incorreta e de } \\
\text { não checagem da } \\
\text { cadeia }\end{array}$ \\
\hline & $\begin{array}{l}\text { Eletricista de } \\
\text { Montagem }\end{array}$ & Na escada & $\begin{array}{l}\text { Observar o } \\
\text { destensionamento, } \\
\text { caso perceba algum } \\
\text { problema na fixação } \\
\text { da cadeia, evitar a } \\
\text { conclusão do mesmo }\end{array}$ & Não observar & $\begin{array}{l}\text { Ocorrem erros } \\
\text { que poderiam } \\
\text { ser corrigidos e } \\
\text { evitados }\end{array}$ \\
\hline & $\begin{array}{l}\text { Eletricista } \\
\text { Encarregado }\end{array}$ & $\begin{array}{l}\text { Na faixa de } \\
\text { servidão }\end{array}$ & Monitorar a atividade & $\begin{array}{l}\text { Não observar } \\
\text { a atividade de } \\
\text { forma adequada }\end{array}$ & $\begin{array}{l}\text { Ocorrem erros } \\
\text { que poderiam } \\
\text { ser corrigidos e } \\
\text { evitados }\end{array}$ \\
\hline
\end{tabular}


memorizada como, por exemplo, o condicionamento físico poderá afetar o controle motor como também a fadiga poderá reduzir o desempenho motor e cognitivo dos eletricistas (DESAULNIERS, 1997) e (WICKENS; HOLLANDS, 2000).

Com a finalidade de superar as deficiências referentes às relações causais entre os FDs e baseando-se nos argumentos acima apresentados, propõe-se o diagrama mostrado na Figura 5. Este diagrama, desenvolvido a partir do modelo IDAC, constitui-se em uma tentativa de aprimoramento para alcançar uma representação mais realista do comportamento dos eletricistas.

O diagrama da Figura 5 apresenta de forma qualitativa a relação de causa e efeito existente entre os FDs. Porém, dependendo das circunstâncias e da relevância que estes fatores representam para a tarefa, os eletricistas podem sofrer influências mais significativas ou menos significativas durante o desempenho da atividade. Modelar estes FDs por RBs permite que seja considerada toda e qualquer relação em que exista pelo menos uma influência mínima.

Assim, a seção seguinte modela as relações de causa e efeito entre os FDs para equipe de manutenção de LTs via RBs.

\section{Redes Bayesianas dos FDs}

As relações de causa e efeito expressas nas RBs dos FDs estão baseadas no diagrama da Figura 5. Para construção destas redes foram selecionados, entre os FDs, apenas os fatores causadores mais significantes para os eletricistas de acordo com as ações executadas (descritas no item Rede Bayesiana da tarefa) e o contexto no qual os eletricistas as desenvolvem. Porém, a rede poderia, a princípio, ser estendida para um maior nível de detalhamento.

Foram construídas quatro diferentes RBs para representar a influência dos FDs nos eletricistas. Assume-se que todas as variáveis dessas redes são dicotômicas. A Tabela 10 mostra os possíveis valores que cada variável da rede pode assumir.

Figura 5: Aprimoramento do diagrama IDAC para uma representação mais realista do comportamento dos eletricistas envolvidos na substituição de cadeias de isoladores.

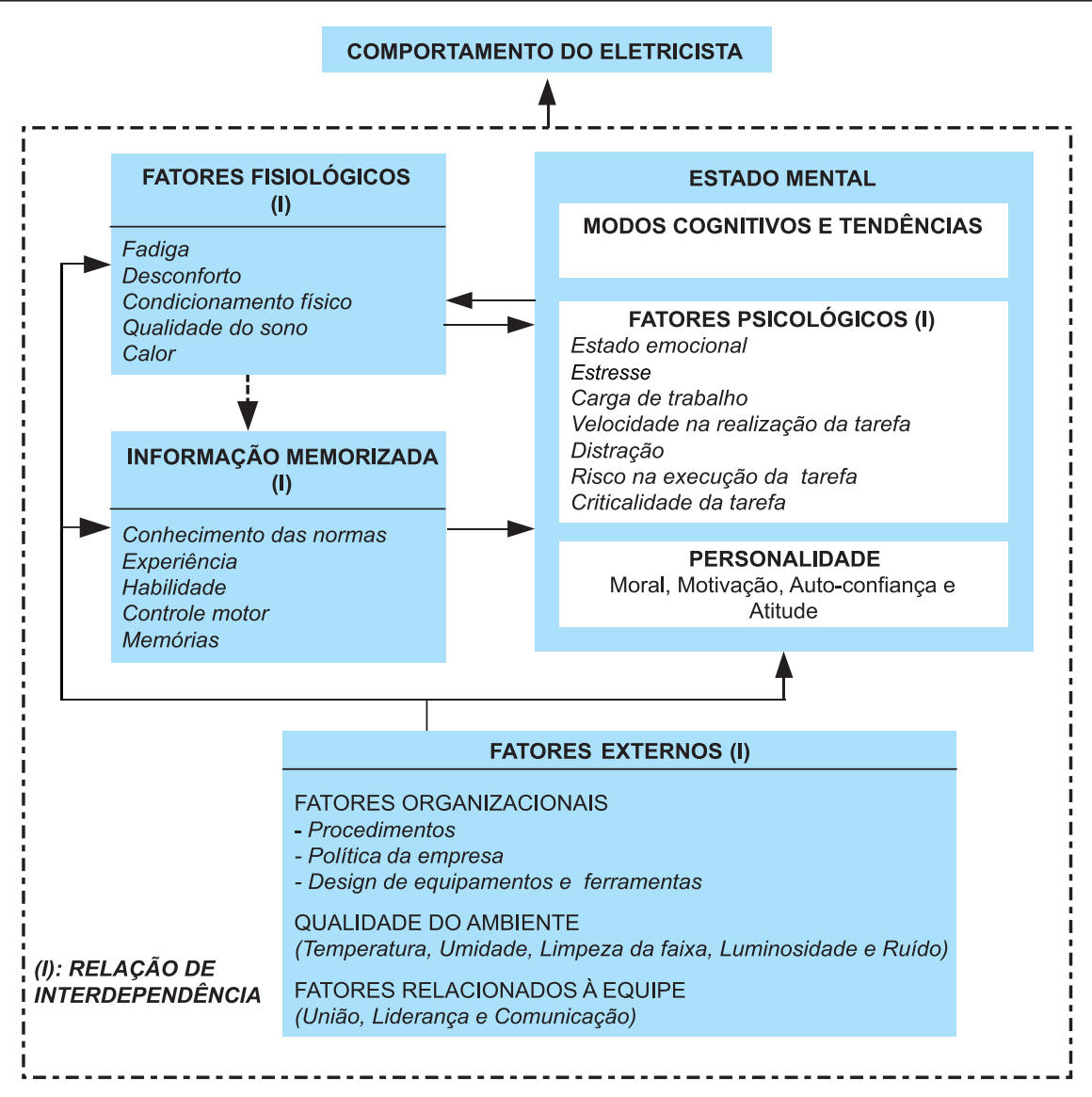


Pelo fato de os eletricistas de montagem e de topo desempenharem funções com características semelhantes, isto é, atividades que necessitam de controle motor e atenção, considera-se os FDs em comum (ver a descrição das atividades realizadas por eletricista em Rede Bayesiana da tarefa). A Figura 6 representa as relações entre os fatores mais relevantes para estes eletricistas. Considera-se que dois fatores podem influenciar a capacidade destes eletricistas ao realizarem suas atividades: controle motor e nível de atenção. É possível, por exemplo, que devido à fadiga e a um condicionamento físico inadequado, estes eletricistas não consigam controlar a velocidade, a força e a precisão dos movimentos necessários para execução da tarefa, isto é, controle motor. Já o nível de atenção pode ser prejudicado pela fadiga e/ou pela presença de agentes distratores, tais como um estado emocional desfavorável e a presença de insetos no local da intervenção.

Considera-se que se o nível de atenção e o controle motor encontram-se adequados, então a capacidade destes eletricistas realizarem a tarefa é ideal. Caso tanto o nível de atenção quanto o controle motor estiverem inadequados, a capacidade está totalmente comprometida. Probabilisticamente, tem-se: com um condicionamento físico inadequado e quando manuseiam equipamentos com design inadequado.

A Figura 7 apresenta a RB dos FDs para o eletricista de apoio. Para este eletricista não foi considerada a influência do controle motor por ser pouco relevante para esta atividade. Conseqüentemente, o eletricista de apoio tem o nível de atenção como o único causador imediato.

A Figura 8 mostra a RB dos FDs para os eletricistas auxiliares. Sendo uma atividade simples na qual os eletricistas necessitam de um certo nível de atenção ao exercerem a operação conjunta de manuseio da linha de mão, considerase que o nível de atenção recebe apenas influências do estado emocional e da fadiga. A fadiga por sua vez, pode ser uma manifestação de uma carga de trabalho excessiva, bem como de um condicionamento físico inadequado.

A Figura 9 mostra a RB dos FDs para o eletricista encarregado. Considera-se que dois fatores podem influenciar este eletricista: comunicação e nível de atenção. A comunicação refere-se a comunicação do eletricista encarregado com os outros eletricistas. Esta é dita inadequada quando existem ruídos, os quais podem ser provenientes da indução eletromagnética, do barulho do vento, entre outros. Percebe-se nesta rede que o encarregado apresenta uma maior probabilidade de estar com seu nível de atenção inadequado quando está fadigado e quando seu estado emocional não está favorável. Considera-se ainda como causa do nível

Percebe-se ainda nesta rede que estes eletricistas apresentam uma maior probabilidade de estarem fadigados quando estão sob uma carga de trabalho excessiva, quando estão de atenção inadequado o fato de os eletricistas não terem cometido erros na etapa anterior. É possível, por exemplo, que o eletricista encarregado tenha o seu nível de atenção di-

Tabela 10: Valores dos FDs.

\begin{tabular}{|c|c|}
\hline Nó & VALORES * \\
\hline NÍVEL DE ATENÇÃO & \{adequado, não adequado\} \\
\hline CAPACIDADE & \{adequada, não adequada\} \\
\hline CARGA DE TRABALHO & \{excessiva, não excessiva\} \\
\hline COMUNICAÇÃO & $\{$ boa, ruim $\}$ \\
\hline CONDICIONAMENTO FÍSICO & \{adequado, não adequado\} \\
\hline CONTROLE MOTOR & \{adequado, não adequado\} \\
\hline DESIGN DE EQUIPAMENTOS & \{adequado, não adequado\} \\
\hline ERROS ANTERIORES & \{ocorreram, não ocorreram\} \\
\hline ESTADO EMOCIONAL & \{favorável, não favorável\} \\
\hline FADIGA & \{presente, não presente\} \\
\hline INSETOS & $\{$ presentes, não presentes\} \\
\hline
\end{tabular}


minuído no momento em que os eletricistas retiram a cadeia velha de isoladores porque ele observou que os eletricistas não cometeram erro na retirada dos contrapinos. Portanto, o fato de a equipe não ter cometido erro na etapa anterior faz com que o encarregado fique mais relaxado e, conseqüentemente, tenha o seu nível de atenção diminuído na etapa presente da intervenção.

Considera-se aqui que, se o nível de atenção e a comunicação do encarregado com os outros eletricistas encontram-se adequados, então este eletricista está monitorando a tarefa corretamente. Caso tanto o nível de atenção quanto a comunicação estiverem inadequados, o monitoramento estará completamente comprometido. Probabilisticamente, tem-se:

$$
\begin{aligned}
& P(E E=0 \mid \text { Nível de atenção }=1, \text { Comunicação }=1)=0 \\
& P(E E=0 \mid \text { Nível de atenção }=0, \text { Comunicação }=0)=1
\end{aligned}
$$

Assim como na Figura 8, a fadiga presente no eletricista encarregado pode ser uma manifestação de uma carga de trabalho excessiva e de um condicionamento físico inadequado.

Figura 6: RBs para os FDs dos EM e ET.

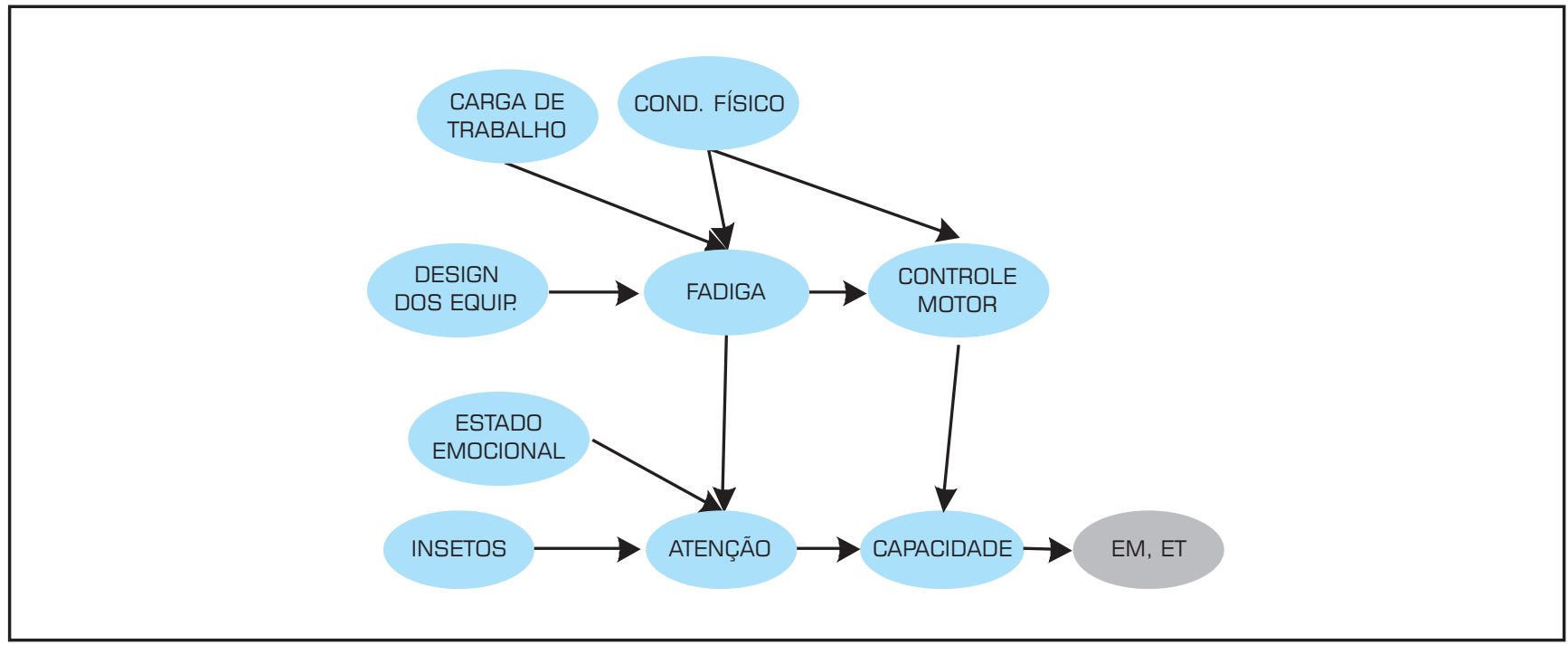

Figura 7: RB para os FDs do EA.

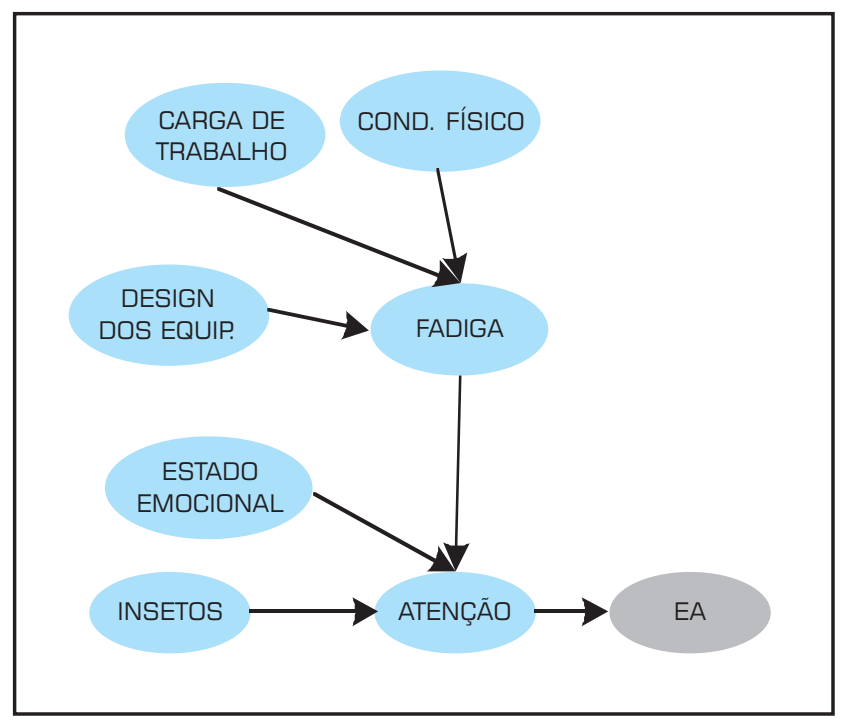

Figura 8: RB para os FDs dos EAUX.

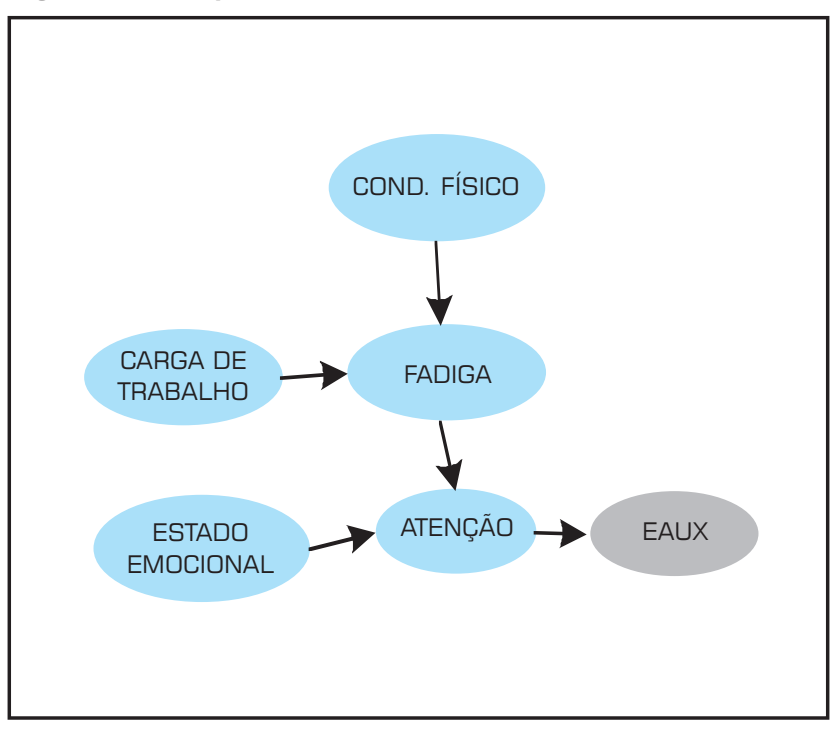




\section{Modelo integrado para ACH}

Para ACH da atividade de manutenção em LTs, as RBs dos FDs apresentadas na seção anterior são agora conectadas à RB da tarefa apresentada na Figura 4. Ou seja, cada eletricista específico desta rede receberá a RB que representa os seus FDs relevantes como, por exemplo, na Figura 10 para o cenário 1 da RB da tarefa.

A integração das RBs dos FDs dos eletricistas, apresentadas em Redes Bayesianas dos FDs, à rede RB dos cenários discutidos em Rede Bayesiana da Tarefa (Figura 4) resulta em um modelo com 53 nós, sendo necessárias 126 probabilidades no processo quantitativo destas redes. Percebe-se que a principal dificuldade encontrada em modelar ações humanas via RBs está na grande quantidade de probabilidades condicionais necessárias para alimentação da rede. Diante deste fato e considerando a escassez de dados relevantes no contexto da atividade de manutenção de LTs, recorreu-se à opinião de especialistas. Dessa forma, as probabilidades do modelo integrado foram eduzidas através de um protocolo de edução proposto por Firmino et al. (2006). Para maiores detalhes sobre a edução das opiniões de especialistas recomenda-se Firmino et al. (2006) e para a edução no contexto de manutenção de LTs, Menêzes e Droguett (2005).

As entrevistas foram realizadas com dois engenheiros e um eletricista. Estes foram eduzidos sobre assuntos diferentes, ou seja, cada especialista foi questionado sobre alguns nós específicos da rede, não havendo sobreposição entre as questões apresentadas pelos especialistas. A amostragem da edução por especialista está apresentada na Tabela 11. Em relação às RBs correspondentes aos FDs dos eletricistas, estas foram eduzidas de um mesmo especialista.

Figura 9: RB para os FDs do EE.

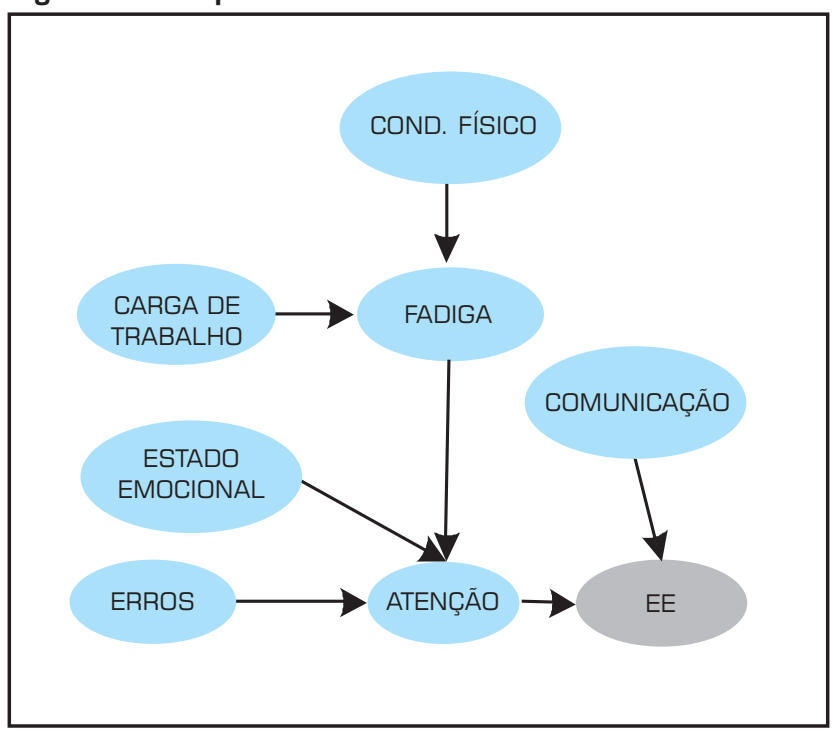

Antes, porém, de apresentar os valores eduzidos dos especialistas e também com o objetivo de auxiliar no entendimento dos resultados obtidos a partir do modelo integrado de confiabilidade humana dado o conjunto de opiniões eduzidas, avalia-se para cada especialista a sua tolerância ao risco. Para tanto, recorreu-se à análise da curva de utilidade de cada especialista. Hammond et al. (1999) apresenta a interpretação da atitude de uma pessoa em relação ao risco a partir de uma curva de utilidade (ver Figura 11), onde uma curva arqueada para cima indica atitude de intolerância ao risco, e quanto maior a curvatura, maior a aversão. Já uma linha reta representa um comportamento neutro, e uma curva arqueada para baixo demonstra disposição para correr risco. Com a finalidade de realizar esta análise, aos especialistas foram expostas alternativas associadas à atividade de substituição de cadeias de isoladores, as quais envolvem decisões de risco. A Figura 12 apresenta a utilidade dos especialistas eduzidos.

Comparando as curvas apresentadas na Figura 12, percebe-se que o especialista A é bastante avesso ao risco, enquanto os especialistas $\mathrm{B}$ e C apresentam um comportamento um pouco semelhante em relação ao risco. Porém, nota-se que o especialista B apresenta uma aversão ao risco um pouco maior que o especialista $\mathrm{C}$.

\section{AVALIAC̣ÃO DA CONFIABILIDADE HUMANA}

Nesta seção, é apresentada a ACH das atividades de manutenção em LTs através do modelo integrado. Sem perda de generalidade, entretanto, o procedimento de modelagem das ações humanas representado pelo modelo integrado é ilustrado através da montagem do cenário 1 (retirada dos

Figura 10: Integração das RBs dos FDs à RB do cenário 1. 
contra-pinos). De fato, a Figura 13 mostra este cenário com as RBs dos FDs conectadas aos seus respectivos nós, onde as variáveis envolvidas podem assumir os valores: favorável (nível $=0$ ) ou desfavorável (nível $=1$ ) ao bom desempenho do sistema.

Os dados obtidos a partir da edução dos especialistas para o cenário 1 são mostrados nas Tabelas 12 a 21 . Note que estas correspondem às distribuições de probabilidades a priori e tabela de probabilidades condicionais (TPCs) de cada variável envolvida no modelo.

Para a variável EE1, por exemplo, tem-se que a probabilidade de o eletricista encarregado não monitorar a retirada dos contra-pinos de forma adequada, dado que ele está com sua atenção inadequada e sua comunicação está adequada, é de $55 \%$.

Tendo-se caracterizado a RB do modelo integrado com as distribuições de probabilidades a priori e condicionais dos seus nós, pode-se utilizar a RB para obter distribuições a posteriori sob a presença de evidências empíricas, subjetivas ou diante da ausência de ambas. Isso fornece grande flexibilidade ao analista, pois é possível verificar a probabilidade de erro humano no momento da execução da tarefa através das observações realizadas sobre o estado do executor, ou seja, sobre o resultado do seu comportamento diante da presença de alguns fatores no momento considerado.

Considere, por exemplo, que é observado que o EE1

Tabela 11: Amostragem da edução dos nós por especialista.

\begin{tabular}{|c|c|c|c|c|c|c|c|c|c|c|c|c|c|}
\hline \multicolumn{2}{|c|}{ CENÁRIO 0 } & \multicolumn{2}{c|}{ GENÁRIO 1 } & \multicolumn{2}{c|}{ GENÁRIO 2 } & \multicolumn{2}{c|}{ GENÁRIO 3 } & \multicolumn{2}{c|}{ GENÁRIO 4 } & \multicolumn{2}{c|}{ GENÁRIO 5 } & \multicolumn{2}{c|}{ GENÁRIO 6 } \\
\hline Nó & ESP. & Nó & ESP. & Nó & ESP. & Nó & ESP. & Nó & ESP. & Nó & ESP. & Nó & ESP. \\
\hline IESO & A & EM1 & B & E*2 & B & EE3 & B & E*4 & C & C5 & B & IES6 & B \\
\hline ETO & A & EE1 & B & IEB2 & C & EAUX3 & B & EA4 & B & EE5 & B & ET6 & B \\
\hline EEO & A & ERROS & B & EA2 & A & ERROS & C & IEB4 & B & ERROS & C & EE6 & B \\
\hline EMO & B & & & EAUX2 & B & & & EA4 & B & & & EM6 & B \\
\hline ERROS & C & & & EE2 & B & & & EAUX4 & C & & & ERROS & B \\
\hline & & & & ERROS & C & & & EE4 & C & & & & \\
\hline & & & & & & & & EM4 & B & & & & \\
\hline
\end{tabular}

Figura 11: Curvas de utilidades.

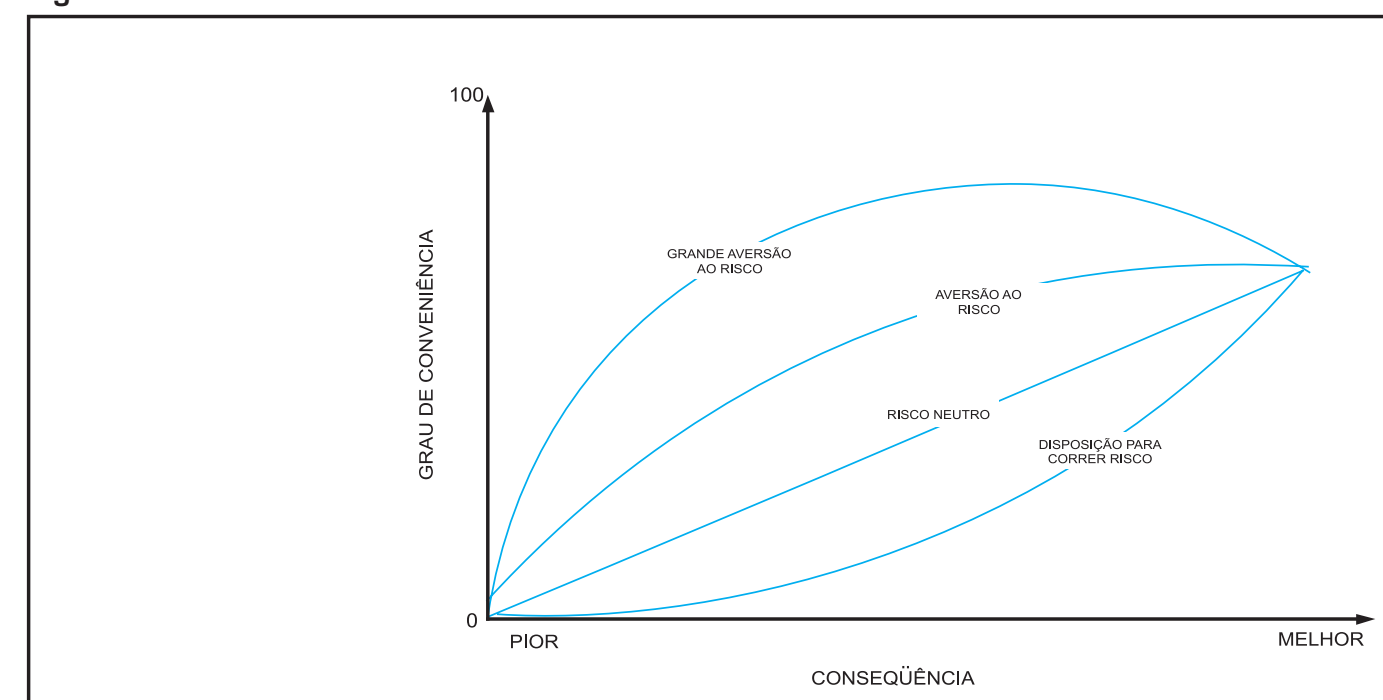


Figuras 12: Curvas de utilidades dos especialistas eduzidos.

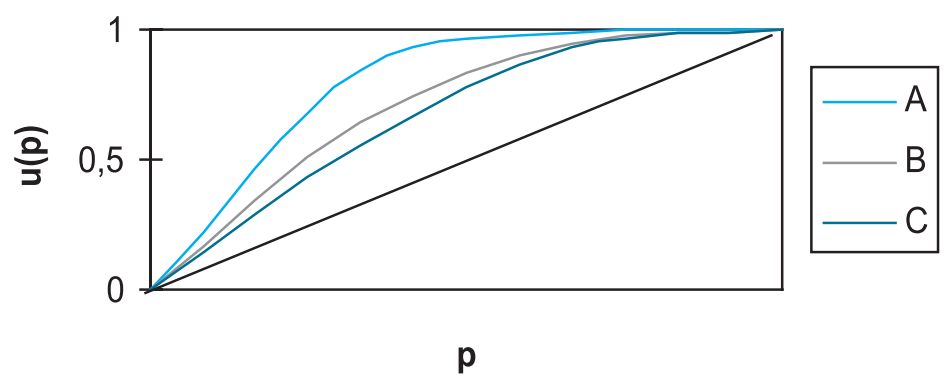

Figura 13: Modelagem do cenário 1.

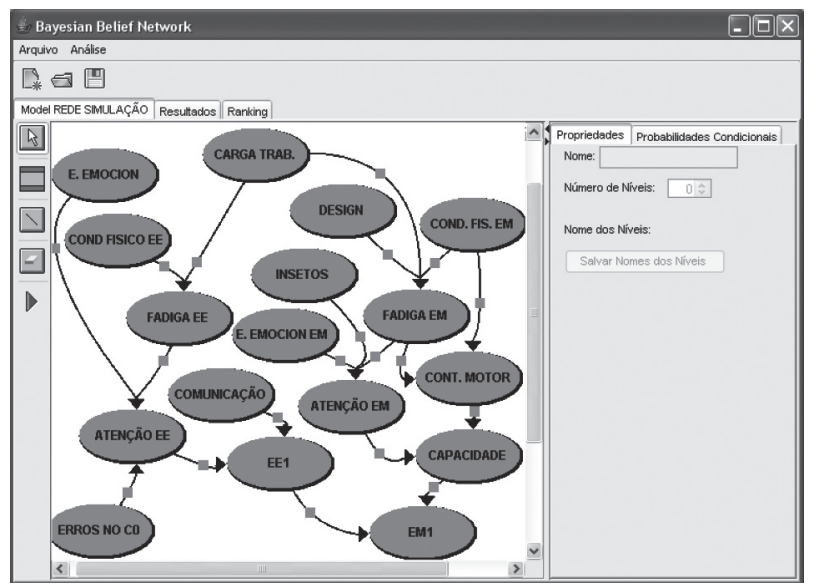

Tabela 12: TPC da atividade do EM1.

\begin{tabular}{|c|c|c|}
\hline EE1, GAPACIDADE & P(EM1=NÍVEL 01 EE1, CAPACIDADE) & P(EM1=NÍVEL 11 EE1, CAPACIDADE) \\
\hline NÍVEL 0, NÍVEL 0 & 0,95 & 0,05 \\
\hline NÍVEL 0, NÍVEL 1 & 0,65 & 0,35 \\
\hline NÍVEL 1, NÍVEL 0 & 0,90 & 0,10 \\
\hline NÍVEL 1, NÍVEL 1 & 0,60 & 0,40 \\
\hline
\end{tabular}

Tabela 13: TPC do monitoramento do EE1.

\begin{tabular}{|c|c|c|}
\hline ATENÇÃO, COMUN. & P(EE1=NÍVEL 0 ATENÇÃO, COMUM.) & P(EE1=NÍVEL 1 ATENÇÃO, COMUM.) \\
\hline NÍVEL 0, NÍVEL 0 & 1,00 & 0,00 \\
\hline NÍVEL 0, NÍVEL 1 & 0,95 & 0,05 \\
\hline NÍVEL 1, NÍVEL 0 & 0,45 & 0,55 \\
\hline NÍVEL 1, NÍVEL 1 & 0,00 & 1,00 \\
\hline
\end{tabular}


Tabela 14: TPC referente aos erros cometidos no cenário anterior.

\begin{tabular}{|c|c|}
\hline P(ERROS COMETIDOS=NÍVEL O) & P(ERROS COMETIDOS=NÍVEL 1) \\
\hline 0.97 & 0.03 \\
\hline
\end{tabular}

Tabela 15: TPC da capacidade dos EM1.

\begin{tabular}{|c|c|c|}
\hline ATENÇÃO, CONT.MOTOR & $\begin{array}{c}\text { P(CAPACID=NÍVEL O\ATENĢÃO, } \\
\text { CONT.MOTOR) }\end{array}$ & $\begin{array}{c}\text { P(GAPACID=NÍVEL 1 ATENÇÃO, } \\
\text { CONT.MOTOR }\end{array}$ \\
\hline NÍVEL 0, NÍVEL O & 1 & 0 \\
\hline NÍVEL 0, NÍVEL 1 & 0,65 & 0,35 \\
\hline NÍVEL 1, NÍVEL O & 0,75 & 0,25 \\
\hline NÍVEL 1, NÍVEL 1 & 0 & 1 \\
\hline
\end{tabular}

Tabela 16: TPC da atenção dos EM1.

\begin{tabular}{|c|c|c|}
\hline INSETOS, EST. EMOC, FADIGA & $\begin{array}{c}\text { P(ATENÇÃO=NÍVEL O\INSETOS, EST. } \\
\text { EMOG, FADIGA) }\end{array}$ & $\begin{array}{c}\text { P(ATENÇÃO=NÍVEL } 1 \backslash \text { INSETOS, } \\
\text { EST. EMOG, FADIGA) }\end{array}$ \\
\hline NÍVEL O, NÍVEL O, NÍVEL O & 0,880 & 0,120 \\
\hline NÍVEL 0, NÍVEL O, NÍVEL 1 & 0,850 & 0,150 \\
\hline NÍVEL 0, NÍVEL 1, NÍVEL O & 0,550 & 0,450 \\
\hline NÍVEL 0, NÍVEL 1, NÍVEL 1 & 0,468 & 0,532 \\
\hline NÍVEL 1, NÍVEL 0, NÍVEL O & 0,950 & 0,050 \\
\hline NÍVEL 1, NÍVEL 0, NÍVEL 1 & 0,808 & 0,192 \\
\hline NÍVEL 1, NÍVEL 1, NÍVEL O & 0,523 & 0,477 \\
\hline NÍVEL 1, NÍVEL 1, NÍVEL 1 & 0,120 & 0,880 \\
\hline
\end{tabular}

Tabela 17: TPC da fadiga do EM1.

\begin{tabular}{|c|c|c|}
\hline DESIGN, G. TRAB, GOND. FIS. & $\begin{array}{l}\text { P(FADIGA=NÍVEL O\ DESIGN, G. } \\
\text { TRAB, GOND. FIS) }\end{array}$ & $\begin{array}{c}\text { P(FADIGA=NÍVEL } 1 \backslash \text { DESIGN, G. } \\
\text { TRAB, GOND. FIS) }\end{array}$ \\
\hline NÍVEL O, NÍVEL O, NÍVEL O & 0,900 & 0,100 \\
\hline NÍVEL 0, NÍVEL 0, NÍVEL 1 & 0,450 & 0,550 \\
\hline NÍVEL 0, NÍVEL 1, NÍVEL O & 0,550 & 0,450 \\
\hline NÍVEL 0, NÍVEL 1, NÍVEL 1 & 0,247 & 0,753 \\
\hline NÍVEL 1, NÍVEL 0, NÍVEL O & 0,750 & 0,250 \\
\hline NÍVEL 1, NÍVEL 0, NÍVEL 1 & 0,337 & 0,663 \\
\hline NÍVEL 1, NÍVEL 1, NÍVEL O & 0,413 & 0,587 \\
\hline NÍVEL 1, NÍVEL 1, NÍVEL 1 & 0,100 & 0,900 \\
\hline
\end{tabular}


está cansado, ou seja, tem-se a evidência empírica (fadiga = nível 1). Pode-se saber a influência que esta evidência tem no insucesso da execução da atividade. Como mostrado na Tabela 22, a probabilidade de monitoramento inadequado do EE1 passa de 0,16 para 0,23 .

Considere agora o caso de evidências subjetivas. Suponha, por exemplo, que sejam disponibilizadas duas opiniões sobre a atenção do EE1 dado que ele foi submetido a uma avaliação específica, $A_{1}=P_{1}$ (aprovação na avaliação tem atenção adequada) $=\beta_{1}(2,1)$ e $A_{2}=P_{2}$ (aprovação na avaliação $\mid$ tem atenção adequada $)=\beta_{2}(4,2)$. Assumindo como válida a condição Markoviana, isto é, as evidências são independentes dado que se sabe sobre a variável a qual estas se referem, pode-se multiplicar as taxas de verossimilhança das evidências disponíveis. De fato, para efeito de cálculos, a evidência é $E^{*}=\beta^{*}(8,2)$. A influência destas evidências sobre a probabilidade de sucesso do EE1 pode ser vista também na Tabela 22.

Como mostrado na Tabela 22, quando se considera apenas as informações eduzidas, a probabilidade do EE1 monitorar a equipe inadequadamente diante do cenário 1 é 0,16 . Esta probabilidade reduz-se para 0,05 se mediante a execução de

Tabela 18: TPC do controle motor dos EM1.

\begin{tabular}{|c|c|c|}
\hline FADIGA, COND. FÍSICO & PIC. MOTOR=NÍVEL OI FADIGA, & $\begin{array}{c}\text { P(G. MOTOR=NÍVEL 1 FADIGA, } \\
\text { COND. FÍSICO) }\end{array}$ \\
\hline NÍVEL 0, NÍVEL O & 0,945 & 0,055 \\
\hline NÍVEL 0, NÍVEL 1 & 0,550 & 0,450 \\
\hline NÍVEL 1, NÍVEL O & 0,450 & 0,550 \\
\hline NÍVEL 1, NÍVEL 1 & 0,250 & 0,750 \\
\hline
\end{tabular}

Tabela 19: TPC da fadiga do EE1.

\begin{tabular}{|c|c|c|}
\hline G. TRAB., COND. FísICO & $\begin{array}{c}\text { PIFADIGA= NÍVEL Ol, G. TRAB., } \\
\text { COND. FISSICO) }\end{array}$ & $\begin{array}{c}\text { P(FADIGA= NÍVEL 11, G. TRAB., } \\
\text { COND. FÍSICO) }\end{array}$ \\
\hline NÍVEL 0, NÍVEL 0 & 0,850 & 0,150 \\
\hline NÍVEL 0, NÍVEL 1 & 0,750 & 0,250 \\
\hline NÍVEL 1, NÍVEL 0 & 0,650 & 0,350 \\
\hline NÍVEL 1, NÍVEL 1 & 0,150 & 0,850 \\
\hline
\end{tabular}

Tabela 20: TPC da atenção do EE1.

\begin{tabular}{|c|c|c|}
\hline E. ANT., EST. EMOC, FADIGA & $\begin{array}{c}\text { P(ATENÇÃ̈O=NÍVEL O\E. ANT., EST. } \\
\text { EMOC, FADIGA) }\end{array}$ & $\begin{array}{l}\text { P(ATENÇÃO=NÍVEL } 1 \backslash \text { E. ANT., } \\
\text { EST. EMOG, FADIGA) }\end{array}$ \\
\hline NÍVEL O, NÍVEL O, NÍVEL O & 0,800 & 0,200 \\
\hline NÍVEL O, NÍVEL O, NÍVEL 1 & 0,650 & 0,350 \\
\hline NÍVEL O, NÍVEL 1, NÍVEL O & 0,550 & 0,450 \\
\hline NÍVEL 0, NÍVEL 1, NÍVEL 1 & 0,357 & 0,643 \\
\hline NÍVEL 1, NÍVEL O, NÍVEL O & 0,750 & 0,250 \\
\hline NÍVEL 1, NÍVEL O, NÍVEL 1 & 0,487 & 0,513 \\
\hline NÍVEL 1, NÍVEL 1, NÍVEL O & 0,412 & 0,588 \\
\hline NÍVEL 1, NÍVEL 1, NÍVEL 1 & 0,200 & 0,800 \\
\hline
\end{tabular}


uma avaliação (evidência subjetiva) for percebido que este eletricista tem maiores chances de ter atenção adequada para monitorar a tarefa solicitada. Por outro lado, observar-se que se o EE1 estiver cansado (evidência empírica) ocorrerá um aumento de $43 \%$ na probabilidade do EE1 monitorar incorretamente a atividade.

Considere agora a $\mathrm{ACH}$ dos eletricistas para os cenários caracterizados na Figura 4 (integração das RBs dos FDs à RB do cenário 1). A Figura 14 apresenta as probabilidades do EE não monitorar corretamente a equipe nos cenários que representam a seqüência da atividade de substituição de cadeias de isoladores. Os cenários 0 e 6 correspondem ao tensionamento e destensionamento do retângulo de forças respectivamente, os quais constituem atividades simétricas. Portanto, esperavase que estas probabilidades fossem próximas. Essa diferença, porém, pode ser justificada com base no fato de que as probabilidades a priori foram eduzidas de especialistas com perfis bastante diferentes (curvas de utilidade apresentadas na Figura 12). $\mathrm{O}$ fato da menor probabilidade ter sido apresentada no cenário 4 , cuja atividade corresponde à colocação da cadeia de isoladores, pode ser justificada devido à criticalidade desta etapa, uma vez que aqui é realizada a pinagem. É importante considerar também que a probabilidade a priori foi eduzida do especialista $\mathrm{C}$, o qual possui a menor aversão ao risco em relação aos outros especialistas.
Com relação aos especialistas de topo, de montagem e auxiliares, a Figura 15 mostra as respectivas probabilidades de erros. Percebe-se que o ET apresenta uma maior probabilidade de erro no cenário 0 quando comparada ao cenário 6. Como já foi comentado, estas atividades são simétricas e possuem o mesmo grau de importância e conseqüência, o que conduz a se esperar probabilidades próximas. No entanto, as probabilidades a priori dos cenários 0 e 6 foram eduzidas dos especialistas A e B, respectivamente, o que pode explicar esta diferença.

Em relação ao EM, pode-se avaliá-lo em duas ocasiões distintas. A primeira corresponde aos cenários 0 e 6 , onde o EM observa o trabalho do ET para poder indicar o instante de parada do tensionamento/destensionamento do retângulo de forças corretamente. A segunda corresponde aos cenários 1 e 4, onde o EM executa a atividade de retirada e colocação dos contrapinos respectivamente. Percebe-se na Tabela 11 que as probabilidades a priori para estas situações foram todas eduzidas do especialista B. Observa-se que no primeiro caso, o EM apresenta probabilidades de erro muito próximas, o que explica a semelhança destes dois cenários. No segundo caso, o EM apresenta uma probabilidade de erro menor no cenário 4 , o que comprova que a colocação dos contrapinos é mais critica e provavelmente requer mais atenção do EM.

Tabela 21: Probabilidades dos nós raízes para o cenário 1.

\begin{tabular}{|c|c|c|}
\hline \multirow{2}{*}{ VARIÁVEL } & \multicolumn{2}{|c|}{ PROBABILIDADES A PRIORI } \\
\cline { 2 - 3 } & NíVEL 0 & NÍVEL1 \\
\hline Carga de trabalho & 0,70 & 0,30 \\
\hline Design de equipamentos do EM1 & 0,90 & 0,10 \\
\hline Condicionamento físico do EM1 & 0,90 & 0,10 \\
\hline Condicionamento físico do EE1 & 0,98 & 0,02 \\
\hline Estado emocional & 0,95 & 0,05 \\
\hline Insetos & 0,90 & 0,10 \\
\hline Comunicação & 0,90 & 0,10 \\
\hline
\end{tabular}

Tabela 22: Análise da variabilidade do comportamento do eletricista encarregado no cenário 1 [EE1] diante de condições específicas.

\begin{tabular}{|c|c|}
\hline EVIDÊNCIA & $\begin{array}{c}\text { P(EE1 NÃO MONITORAR CORRETAMENTE A } \\
\text { EQUIPE No G1) }\end{array}$ \\
\hline nenhuma & 0,16 \\
\hline$B(2,1)$ e $\beta(4,2)$ sobre a atenção adequada do EE1 & 0,05 \\
\hline Fadiga presente no EE1 & 0,23 \\
\hline
\end{tabular}


Quanto à operação conjunta dos eletricistas de Topo e de Montagem, percebe-se que estes apresentam uma probabilidade de erro menor no cenário 4 quando comparada ao cenário 2. Estas atividades também são simétricas e possuem o mesmo grau de importância e conseqüência, o que conduziu a resultados próximos. A diferença pode ser explicada pelo fato de as probabilidades a priori dos nós referentes aos $\mathrm{E}^{*}(\mathrm{ET}+\mathrm{EM})$ nos cenários 2 e 4 terem sido eduzidas dos especialistas $\mathrm{B}$ e $\mathrm{C}$ respectivamente, onde $\mathrm{C}$ é menos avesso ao risco que $B$.

Os eletricistas auxiliares podem ser avaliados em duas ocasiões distintas. A primeira corresponde à ação de segurar a linha de mão que é realizada nos cenários 2 e 4, enquanto os eletricistas retiram a cadeia velha e colocam a cadeia nova. A segunda corresponde à ação de conduzir a subida/descida de isoladores através da linha de mão realizada no cenário 3. Percebe-se no primeiro caso que a $\mathrm{PEH}$ no cenário 2 é maior que a do cenário 4. Apesar de serem atividades simétricas, a diferença também pode ser compreendida pelo fato de $\mathrm{C}$ ser menos avesso ao risco que B. Já no segundo caso, a probabilidade desses eletricistas realizarem a operação de forma incorreta é bastante significativa (aproximadamente 0,15). Este resultado parece ter sido influenciado pela elevada probabilidade $a$ priori para esta situação que foi eduzida do especialista $\mathrm{B}, \mathrm{o}$ qual possui um nível de aversão ao risco intermediário em relação aos outros especialistas. Dessa forma, pode-se concluir que esta atividade apresenta uma probabilidade de ocorrência relevante dos erros descritos na Tabela 6.

Figura 14: Probabilidades do EE monitorar de forma inadequada os cenários da rede.

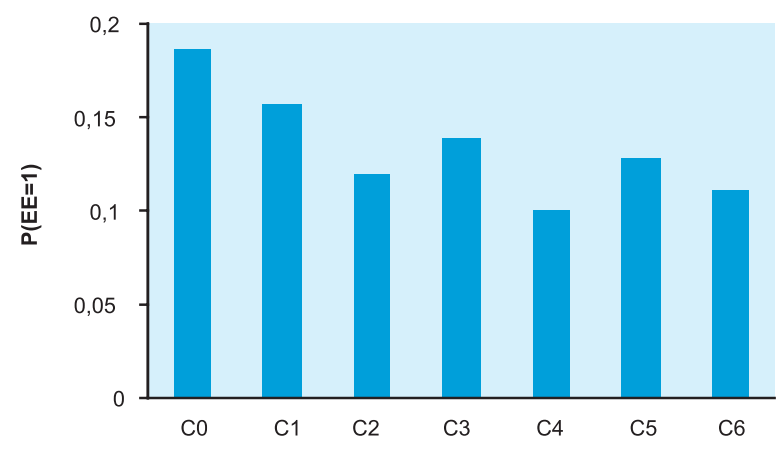

Figura 15: Probabilidades de erros dos eletricistas de topo, montagem e auxiliares nos cenários.

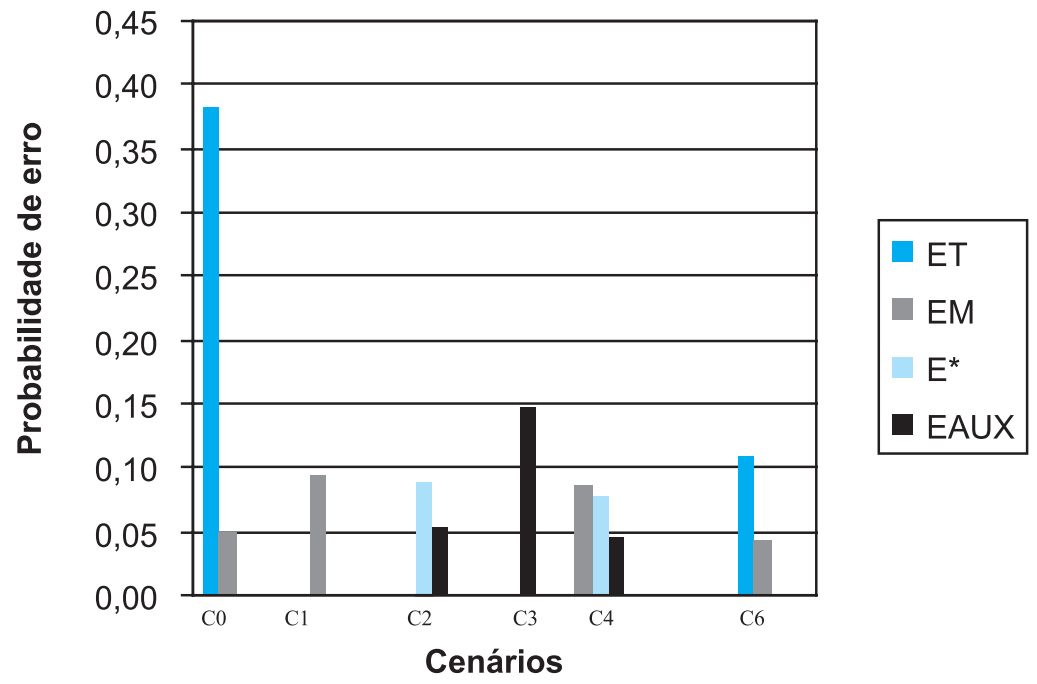


Com relação ao eletricista de apoio, as probabilidades de erro nos cenários 2 e 4 são iguais a 0,25 e 0,23 , respectivamente (veja Figura 16). Esperava-se que estas probabilidades fossem menores, uma vez que se trata da atividade mais simples quando comparada com as atividades dos outros eletricistas que sobem na estrutura. No entanto, as probabilidades a priori para este eletricista foram eduzidas do especialista $\mathrm{A}$, o que talvez justifique estes números.

A operação conjunta dos eletricistas de montagem e apoio (C5) consiste no engate do concha-garfo, cujo erro associado corresponde à não verificação da fixação da cadeia após o engate (veja Tabela 10). Este erro poderá deixar a cadeia instável e susceptível a problemas mais sérios nas atividades posteriores. Como mostrado na Figura 16, a probabilidade de erro é 0,082 , o que pode ser interpretado como a ocorrência média de 8 erros em 100 intervenções.

\section{CONCLUSÕES}

Neste artigo foi proposta e discutida uma metodologia para a ACH baseada em RBs. Dentro do contexto da metodologia proposta, discute-se inicialmente a finalidade e importância da coleta de informações através da familiarização com o procedimento em análise. Foi demonstrado também como as informações obtidas podem ser organizadas através da HTA. Em seguida, foi comentada a análise qualitativa via RBs, em que foi ressaltada a importância de representar as interações existentes nas ações humanas, a dinâmica existente entre elas, bem como a necessidade de identificar os prováveis erros humanos. A identificação de tais erros possi- bilita um melhor entendimento do comportamento humano, permitindo que pelos prováveis erros humanos relatados sejam conhecidas as suas prováveis causas. Em seguida, foi apresentado o modelo para $\mathrm{ACH}$ através da integração das RBs dos FDs à RB da tarefa, e a sua quantificação e avaliação.

\section{FDs são todos os fatores que de alguma forma afetam a confiabilidade humana e conseqüentemente auxiliam na} determinação da PEH.

Em se tratando das relações de causa e efeito para construção de RBs dos FDs, foi observada na literatura a ausência de algumas relações causais, o que conduziu a um aprimoramento dessas relações para uma representação mais realista do comportamento humano.

Pôde-se perceber que as características de RBs contribuem no sentido de suprimir as principais deficiências encontradas nos métodos de $\mathrm{ACH}$ tradicionais. Entre outras vantagens de RBs, este artigo mostrou que a atualização de RBs através de inferências subjetivas e empíricas constituem uma grande ferramenta para monitorar problemas gerencias e operacionais. Apesar das vantagens de se utilizar uma metodologia baseada em RBs, pôde-se perceber limitações práticas, tais como o elevado número de probabilidades condicionais a serem obtidas, que, conjuntamente com a escassez de dados, constitui no principal limitante para a ACH via RBs. Neste sentido, entretanto, tal problema foi solucionado com a edução de especialistas através de um protocolo de

Figura 16: Probabilidades de erros dos eletricistas de apoio e operação conjunta dos eletricistas de apoio e montagem nos cenários.

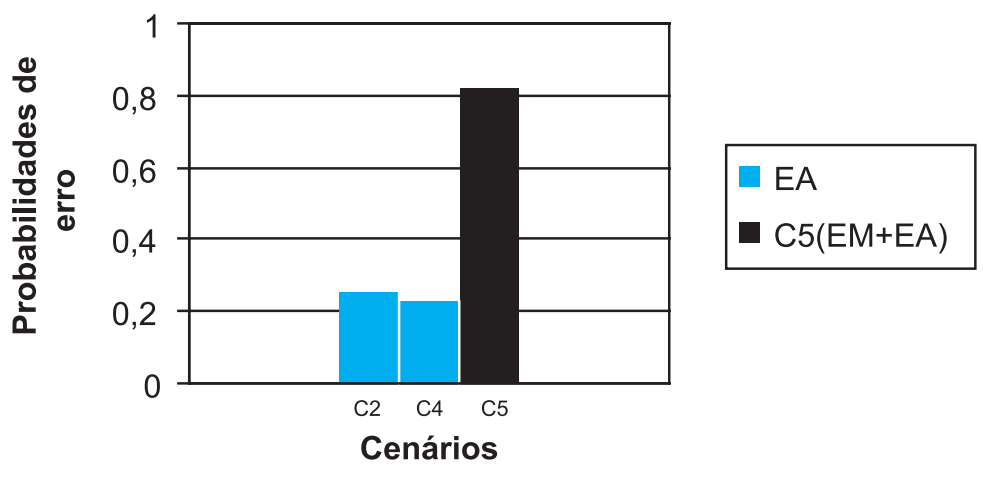


edução proposto por Firmino et al. (2006). Com o objetivo de tentar solucionar o problema da inexistência de dados empíricos de erro humano para o contexto analisado, assim como de servir de referência para contornar as estimativas obtidas pelo modelo proposto, o desenvolvimento de um banco de dados para a análise de confiabilidade humana é objeto atual de pesquisa dos autores.

A metodologia proposta foi então aplicada no contexto de ACH para manutenção de linhas de transmissão. As opiniões eduzidas foram avaliadas através da análise da curva de utilidade. Pôde-se perceber algumas discrepâncias nos resultados provindos das modelagens dos dados obtidos através da edução realizada. Uma possível alternativa de solução seria consultar mais de um especialista sobre a mesma probabilidade e assim fazer agregação dos mesmos via metodologia proposta por Droguett et al. (2004). Finalmente, este artigo enfatizou que as relações de causa e efeito devem ser aplicadas para fazer o reconhecimento do erro humano, pois estas relações providenciam caminhos mais consistentes para caracterizar estes erros.

\section{Artigo recebido em 22/08/2005 Aprovado para publicação em 06/09/2006}

\section{- Referências}

CHANG, Y. H.: MOSLEH, A. Cognitive modeling and dynamic probabilistic simulation of operating crew response to complex system accidents (ADSIDACrew). Center for Technology Risk Studies. University of Maryland, 1999.

COMER, M. K.; SEAVER, D. A.; STILLWELL, W. G.; GADDY, C. D. General human reliability estimates using expert judgment (NUREG/CR-3688). Washington, DC: U. S Nuclear Regulatory Commission, 1984.

COOPER, S. E.; RAMEY-SMITH, A. M. WREATHALL, J.; PARRY, G. W., BLEY, D. C.; LUCKAS, W. J.; TAYLOR, J. H.; BARRIERE, M. T. A technique for human error analysis (ATHEANA) (NUREG/CR-6350) Washington, DC:US Nuclear Regulatory Commission, 1996.

DESAULNIERS, D. R. Stress in the control room: effects and solutions. Washington, D.C. 20555: U. S. Nuclear Regulatory Commission, 1997.

DROGUETT, E. L.; GROEN, F; MOSLEH, A. The combined use data and expert estimates in population variability analysis. Reliability Engineering and Systems Safety. v. 83, p. 311-321, 2004.

EMBREY, D.E.; HUMPHREYS, P.; ROSA, E. A.; KIRWAN, B.; REA, K. SLIM-MAUD. An approach to assessing human error probabilities using structured expert judgment (NUREG/CR-3518). Washington, D.C. USNRC, 1984.

FIRMINO, P. R.; DROGUETT, E. L. Redes Bayesianas para a parametrização da confiabilidade em sistemas complexos. Engenharia de Produção, Universidade Federal de
Pernambuco, Centro de Tecnologia e Geociências, 2004

FIRMINO, P. R.; MENÊZES, R. C.; DROGUETT, E. L.; DUARTE, D. L. Eliciting Engineering Judgments in Human Reliability Assessment. Artigo submetido e aceito para o Annual Reliability \& Maintainability Symposium (RAMS) 2006. California - EUA, 2006

GERTMAN, D. I.; BLACKMAN, H. S.; HANEY, L. N.; SEIDLER, K. S.; SULLIVAN, C.; HAHN, H. A. INTENT: A method for estimating human error probabilities for errors of intention (EGG-SRE 9178). Idaho Falls, ID: Idaho National Engineering Laboratory, 1990.

GERTMAN, D. I. Representing cognitive activities and error in HRA tree (EGG-HFRU10026). Idaho Falls, ID: Idaho National Engineering Laboratory, 1992.

GERTMAN, D. I. Representing cognitive activities and error in HRA tree. Reliability Engineering and Systems Safety, v. 39, p. 25-34, 1993.

GERTMAN, D. I.; BLACKMAN, H. S. Human reliability \& safety analysis data handbook. New York: John Wiley \& Sons, Inc., 1994.

HAMMOND, J. S.; KEENEY, R. L.; RAIFFA, H. Somos movidos a decisões, decisões inteligentes: como avaliar alternativas e tomar a melhor decisão. 5.ed. Rio de Janeiro, Campus, 1999.
HANEY, L. N.; BLACKMAN, H. S.; BELL, B. J.; ROSE, S. E.; HESSE, D. J.; MINTON, L. A.; JENKINS, J. P. Comparison and application of quantitative human reliability analysis methods for the risk method integration and evaluation program (RMIEP) (NUREG/ CR-4835). Washington, DC: US Nuclear Regulatory Commission, 1989.

HANNAMAN, G. W.; SPURGIN, A. J.; LUKIC, Y. D. Human cognitive reliability model for PRA analysis (NUS-4531). Palo Alto, CA: Electric Power Research Institute, 1984.

HOLLNAGEL, E. Cognitive Reliability and Error Analysis Method. England: Elsevier Science, 1998.

KIM, I. S. Human reliability analysis in the man-machine interface design review. Annals of Nuclear Energy. v. 28, p. 1069-1081, 2001.

KIRWAN, B. A guide to practical human reliability assessment. London: Taylor \& Francis, 1994.

KIRWAN, B.; AINSWORTH, L. K. A Guide to Task Analysis. Washington, DC: Taylor \& Francis, 1993.

KORB, K. B.; NICHOLSON, A. E. Bayesian artificial intelligence. Florida: Chapman \& Hall/CRC, 2003.

LUCAS, D. State of the art review of qualitative modelling techniques. Dalton, Lancs. UK: Human Reliability Associates, 1988.
MACWAN, A.; MOSLEH, A. A methodology for modelling operator errors of commission in probabilistic risk assessment. Reliability Engineering and Systems Safety. v. 45, p. 139-157, 1994.

MENÊZES, R. C.; DROGUETT, E. L. Uma metodologia para a Avaliação da Confiabilidade Humana em atividades de substituição de cadeias de isoladores em linhas de transmissão. Engenharia de Produção, Universidade Federal de Pernambuco, Centro de Tecnologia e Geociências, 2005.

MENÊZES, R. C.; FIRMINO, P. R.; DROGUETT, E. L. Análise de confiabilidade humana via redes Bayesianas. Artigo completo submetido e aceito para o SBPO 2005. Rio Grande do Sul, 2005.

MOSLEH, A.; CHANG, Y. H. Model-based human reliability analysis: prospects and requirements. Reliability Engineering and System Safety. v. 83, p. 241-253, 2004.

PARRY, G. W.; MOSLEH, A. Control room crew operations research project (EPRI TR105280). Palo Alto, CA: Electrical Power Research Institute, 1995.

PEARL, J. Probabilistic Reasoning in Intelligent Systems: Networks of Plausible Inference. 2.ed. California: Morgan Kaufmann, 1998.

PHILLIPS, L. D.; HUMPHREYS, P. C.; EMBREY D. E. A socio-technical approach to assessing human reliability (83-4). OAK Ridge, TN: OAK Ridge National Laboratory, 1983. 


\section{- Referências}

POTASH, L. M.; DIETZ, P. E.; LEWIS, C. M.; DOUGHERTY, E. M. Jr. Experience in integrating the operator contributions in the PRA of actual operating plants. (ANS/ ENS Topical Meeting on Probabilistic Risk Assessment, Port Chester, NY) LaGrange, IL: American Nuclear Society, 1981.

SIEGEL, A. I.; BARTTER, W. D.; WOLFF, J. J.; KNEE, H. E.; HAAS, P. M. Maintenance personnel performance simulation (MAPPS) model (NUREG/CR-3626). Washington, DC:
U. S. Nuclear Regulatory Commission, 1984

SPURGIN, A. J.; MOIENI, P. An evaluation of current human reliability assessment methods. In G. APOSTOLAKIS (Ed), Probabilistic safety assessment and management. New York: Elsevier, 1991.

SWAIN, A. D. Comparative evaluation of methods for human reliability analysis (CRS-71). Garching, FRC: Gesellschaft fur Reaktorsicherheit, 1989.
SWAIN, A. D; GUTTMANN, H. E. Handbook of Human Reliability Analysis with Emphasis on Nuclear Power Plant Applications. Washington: US Nuclear Regulatory Commission, 1983.

WICKENS, C.D.; HOLLANDS, J. G. Engineering Psychology and Human Performance. New Jersey: Prentice Hall. 2000

WOODS, D. D.; ROTH, E. M.; POPLE, H. JR. Modeling human intention forma- tion for human reliability assessment In G. E. APOSTOLAKIS, P. K.; MANCINI, G. (Eds.), Accident sequence modelling Human actions, system response, intelligent decision support. London: Elsevier Applied Science, 1988

WREATHALL, J. Operator action trees. An approach to quantifying operator error probability during accident sequences, NUS4159. San Diego, CA: NUS Corporation, 1982

- Sobre os autores

\section{Enrique López Droguett}

UFPE, Ph.D.

End.: Av. Acadêmico Helio Ramos, s/n - Cidade Universitária - 50740-530 - Recife - PE

Tels.: (81) 2126-8728 (ramal 36) Fax: (81) 2126-8728 (ramal 30)

E-mail: ealopez@ufpe.br

\section{Regilda da Costa Silva Menêzes}

UFPE, MSc.

End.: Av. Acadêmico Helio Ramos, s/n - Cidade Universitária - 50740-530 - Recife - PE

Tels.: (81) 2126-8728 (ramal 33), (81) 3361-2871, (81) 8845-4255 Fax: (81) 2126-8728 (ramal 30)

E-mail: regildamenezes@yahoo.com.br 